\title{
The validation status of blood biomarkers of amyloid and phospho-tau assessed with the 5-phase development framework for AD biomarkers
}

\author{
N. J. Ashton ${ }^{1,2,3}$ (D) A. Leuzy ${ }^{4}$ T. K. Karikari ${ }^{1}$ - N. Mattsson-Carlgren ${ }^{4,5,6} \cdot$ A. Dodich $^{7,8} \cdot$ M. Boccardi ${ }^{9,10} \cdot$ J. Corre $^{11}$. \\ A. Drzezga ${ }^{12} \cdot$ A. Nordberg ${ }^{13,14} \cdot$ R. Ossenkoppele ${ }^{4,15} \cdot$ H. Zetterberg ${ }^{1,16,17,18} \cdot$ K. Blennow $^{1,16} \cdot$ G. B. Frisoni ${ }^{9,19}$. \\ V. Garibotto ${ }^{7,20} \cdot$ O. Hansson $4,18,21$
}

Received: 3 November 2020 / Accepted: 9 February 2021 / Published online: 6 March 2021

(C) The Author(s) 2021

\begin{abstract}
Purpose The development of blood biomarkers that reflect Alzheimer's disease (AD) pathophysiology (phosphorylated tau and amyloid- $\beta$ ) has offered potential as scalable tests for dementia differential diagnosis and early detection. In 2019 , the Geneva AD Biomarker Roadmap Initiative included blood biomarkers in the systematic validation of AD biomarkers.

Methods A panel of experts convened in November 2019 at a two-day workshop in Geneva. The level of maturity (fully achieved, partly achieved, preliminary evidence, not achieved, unsuccessful) of blood biomarkers was assessed based on the Biomarker Roadmap methodology and discussed fully during the workshop which also evaluated cerebrospinal fluid (CSF) and positron emission tomography (PET) biomarkers.

Results Plasma p-tau has shown analytical validity (phase 2 primary aim 1) and first evidence of clinical validity (phase 3 primary aim 1), whereas the maturity level for $A \beta$ remains to be partially achieved. Full and partial achievement has been assigned to $p-$ tau and $\mathrm{A} \beta$, respectively, in their associations to ante-mortem measures (phase 2 secondary aim 2). However, only preliminary evidence exists for the influence of covariates, assay comparison and cut-off criteria.

Conclusions Despite the relative infancy of blood biomarkers, in comparison to CSF biomarkers, much has already been achieved for phases 1 through 3 - with p-tau having greater success in detecting AD and predicting disease progression. However, sufficient data about the effect of covariates on the biomarker measurement is lacking. No phase 4 (real-world performance) or phase 5 (assessment of impact/cost) aim has been tested, thus not achieved.
\end{abstract}

Keywords Alzheimer's disease $\cdot$ Blood $\cdot$ Strategic roadmap $\cdot$ A $\beta 42 \cdot$ A $\beta 40 \cdot$ P-tau

\section{Introduction}

The "Biomarker Roadmap" initiative was established in 2017 after adapting an oncology methodological framework [1] for the systematic assessment of biomarker validation in Alzheimer's disease (AD) [2]. Using this 5-phase framework, previous reviews have already assessed the validation and

This article is part of the Topical Collection on Neurology.

N. J. Ashton

nicholas.ashton@gu.se

O. Hansson

Oskar.Hansson@med.lu.se

Extended author information available on the last page of the article maturity status of well-consolidated biomarkers [3-8]. The Biomarker Roadmap Initiative framework also included the systematic validation of cerebrospinal fluid (CSF) AD biomarkers [9], with recent updates [10]. However, the 2017 framework did not include the assessment of blood biomarkers since robust evidence of blood biomarkers specific for AD pathophysiology was lacking [11].

A blood biomarker offers the opportunity for a widely accessible triage for the rapid assessment of patients in primary care or the identification of appropriate individuals for recruitment into therapeutic trials. While the concept of a blood biomarker for dementia certainly predates the studies examined in this review $[12,13]$, large-scale explorative omics have failed to identify robust biomarkers for $\mathrm{AD}$ dementia or the underlying pathology [14-18]. Instead, due to the advancement of targeted proteomic technologies and the emergence of 
well-characterized research cohorts (e.g. Alzheimer's Disease Neuroimaging Initiative (ADNI) and Swedish BioFINDER), the blood biomarkers assessed today are largely based on those already established in CSF [19].

This review focuses on the recent advancements in amyloid- $\beta(A \beta)$ and phosphorylated tau (p-tau) as leading blood biomarkers that identify $\mathrm{AD}$ and its underlying pathology [20]. Though we recognize that neurofilament light (NfL) and total tau (t-tau) have been widely investigated in the context of $\mathrm{AD}$, they are not considered in this review due to nondisease specificity for AD (NfL) or lack of clear disease association (t-tau). Concentrations of blood (plasma or serum) NfL have been shown to be robustly, albeit moderately, increased in MCI and AD [21-25]. Yet, NfL is a well-established measure of global neuronal injury in many neurodegenerative diseases [26, 27] and acute neurological disorders [28]. Thus, NfL does not have the required specificity to be classified as an "AD biomarker". Plasma t-tau has also been investigated widely in $\mathrm{AD}[25,29,30]$, yet these studies have concluded that plasma t-tau, certainly in its current immunoassay format, only shows minor changes with large overlaps with disease controls to have clinical relevance for AD. Recent studies, despite being preliminary, have suggested that associations with $\mathrm{AD}$ can be achieved by measuring t-tau using an assay format directed toward the $\mathrm{N}$-terminal region of the tau protein in blood [31, 32].

Since the last Biomarker Roadmap Initiative framework in 2017, which included CSF biomarkers [9], blood biomarkers have made substantial progress. Ultrasensitive immunoassays (p-tau and $A \beta$ ), fully automated immunoassays $(A \beta)$ and immunoprecipitation mass spectrometry (IPMS; $A \beta$ ) methods have been widely reported in large cohorts, predominately defined by CSF biomarkers or in vivo $\mathrm{A} \beta$ positron emission tomography (PET). Therefore, the aim of this work is to begin assessing $\mathrm{AD}$ blood biomarkers based on the 5-phase framework Biomarker Roadmap methodology.

\section{Methods}

\section{Target}

As mentioned previously, this study was performed with reference to a model imported from the oncology field [1] and adapted to the landscape of AD biomarkers. This literature review examines the validation status of blood $p$-tau ( $p$ tau181 and $p$-tau217) and $A \beta(A \beta 42$ or $A \beta$ ratios) as $A D$ biomarkers, in accordance with the 2020 update [33] of the Biomarker Roadmap [2, 3]. For the purposes of this review, all target populations are discussed; $\mathrm{AD}, \mathrm{AD}$ dementia, $\mathrm{MCI}$ and non- $\mathrm{AD}$ neurodegenerative disorders, as defined below. Data on familial AD is not the focus of this effort, and data obtained in autosomal-dominant $\mathrm{AD}$ are only considered when data in sporadic AD are not available and are not considered for assessing the biomarker maturity. All studies that included targeted blood measures of $p$-tau and $A \beta$ (e.g. not explorative proteomics) after 2016 were considered. If publicly available data had been utilized for analysis (e.g. ADNI), only the most appropriate study was included in each phase/ aim, thus avoiding repeated data and overinterpretation of findings.

\section{Glossary}

Table 1 denotes the terms for this review.

\section{Conceptual framework}

The conceptual framework for this review stems from the field of oncology [1] and has been described in detail by Boccardi et al. [2] and updated in 2021 [33]. Here, we summarize the application of this methodological framework to the use of blood AD biomarkers, namely $p$-tau and $A \beta$, for diagnostic purposes in routine clinical settings. Specifically, all aims are qualified as "fully achieved", "partly achieved", "preliminary evidence" or "not achieved" based on the available evidence.

\section{Phase 1}

Phase 1 studies investigate the rationale for using blood $\mathrm{p}$-tau and $\mathrm{A} \beta$ for the diagnosis of $\mathrm{AD}$ and $\mathrm{AD}$ dementia.

\section{Phase 2}

Phase 2 aims to define the ability of blood biomarkers to discriminate patients with $\mathrm{AD}$ dementia from cognitively unimpaired (CU) and more importantly from non-AD dementias. Phase 2 also defines the clinical assay employed for biomarker measurement and assesses comparisons between assay formats. This phase also aims at identifying possible differential effects of covariates (e.g. age, gender, apolipoprotein $\varepsilon 4$ (APOE ع4) status) in patients and $\mathrm{CU}$, which may influence the concentrations levels of these biomarkers independently from the disease pathophysiology.

\section{Phase 3}

Phase 3 studies assess the ability of AD blood biomarkers to detect prodromal disease, e.g. the ability to predict future development of AD dementia in patients with MCI. Given that the large majority of blood biomarker studies are endophenotyped by CSF or PET A $\beta$, we can also investigate the association to preclinical disease (cognitively unimpaired but underlying pathology (CU+)). Phase 3 studies aim to 
define criteria for positivity ( $\mathrm{AD}$ or $\mathrm{A} \beta+$ ), to compare the diagnostic performance with other biomarkers and to assess the diagnostic value of combinations of biomarkers with a view to defining biomarker-based algorithms.

\section{Phase 4}

Phase 4 studies assess the performance of blood biomarkers in representative patient cohorts from primary care or memory clinics. The biomarker should have been used to support a clinical diagnosis to patients who are subsequently treated based on the biomarker in question. Phase 4 assesses the benefit of a blood biomarker in early disease detection, as well as their practical feasibility and associated protocol compliance. Preliminary evidence about costs is an additional aim, in view of dedicated studies in phase 5. Phase 4 has not been yet started and will not be discussed in this review.

\section{Phase 5}

Phase 5 studies evaluate the impact of diagnosis based on blood biomarker biomarkers on society (e.g. costeffectiveness relative to clinically meaningful outcomes). Phase 5 has not yet started and will not be discussed in this review.

\section{Evidence assessment}

For each of these phases mentioned above, evidence was searched in the literature by two independent raters (NJA and JC) and subsequently assessed to evaluate whether each aim and sub-aim was achieved, partly achieved, preliminarily investigated, or not achieved or not addressed (Table 2).

\section{Search for and selection of papers}

The phase aim and sub-aim-specific PubMed search strings are provided as an online resource https://drive.switch.ch/ index.php/s/4reUTSuqNZHyIC8.

\section{Results}

Figure 1A (p-tau) and Fig. 1B (A $\beta$ ) provide an overview of the current validation status of blood biomarkers according to our methodological framework.

\section{Phase 1: preclinical exploratory studies}

The aim of phase 1 studies is to identify characteristics unique to $\mathrm{AD}$ that might lead to ideas for clinical tests for detecting AD.

\section{Phase 1: primary aim}

The primary aim of phase 1 is to identify leads for potential biomarkers and to prioritize such identified targets. The idea of a blood biomarker follows the same rationale as for the development of CSF biomarkers for $\mathrm{AD}$, detailed in the 2017 Biomarker Roadmap by Mattsson et al. [9]. The identification of truncated N-terminus $A \beta$ [41] - later $A \beta 42$ in extracellular plaques [42] - tau being identified as a

Table 1 Glossary term

\begin{tabular}{ll}
\hline Term & Meaning \\
\hline Alzheimer's disease & $\begin{array}{c}\text { The presence of extracellular A } \beta \text { plaques and aggregates of } \\
\text { hyperphosphorylated tau in NFTs. These features define AD } \\
\text { independently of the clinical expression of cognitive symptoms [34] } \\
\text { The developed and progressive decline in memory and other cognitive } \\
\text { functions leading to functional impairment in activities in everyday life. } \\
\text { Criteria are defined by the National Institute of Neurological and } \\
\text { Communicative Disorders and Stroke and the Alzheimer's Disease and } \\
\text { Related Disorders Association criteria [35]. Due to clinical criteria only, } \\
\text { AD dementia cases will have non-AD pathology or mixed AD and } \\
\text { other types of pathology [36] } \\
\text { This refers to individuals without, or with subtle, functional disability but } \\
\text { with an acquired objective cognitive impairment. Representing a } \\
\text { clinical syndrome, it encompasses cases progressing to AD (about } \\
\text { 40-60\%) or non-AD dementia (about 10\%-30\%; [37, 38] as well cases } \\
\text { who are stable during several years (about 30-50\%). MCI cases } \\
\text { positive for AD biomarkers can be defined as prodromal AD based on } \\
\text { research diagnostic criteria [39, 40] } \\
\text { Refers to all neurodegenerative disorders considered in the context of AD } \\
\text { differential diagnosis. The term is considered independent of the } \\
\text { clinical manifestations of these diseases }\end{array}$ \\
Non-Alzheimer's disease & \\
neurodegenerative disorder &
\end{tabular}


Table 2 Assessment criteria for the Biomarker Roadmap

Fully achieved

Partly achieved

Preliminary evidence

Not achieved

Unsuccessful
Available scientific evidence successfully replicated in properly powered and well-designed studies.

Methodologically sound and well-powered studies have provided convincing evidence that has been replicated

The available evidence is not sufficiently replicated, or samples are not adequately powered, or studies are faulted with major methodological limitations

Only preliminary evidence is available

Studies are not yet performed at the time of the review

Available scientific evidence shows a failure for the biomarker in achieving the aim. Findings in the subsequent roadmap phases should be interpreted with caution

a

\begin{tabular}{|c|c|c|c|c|c|c|c|c|c|}
\hline \multicolumn{10}{|c|}{ Development of blood phosphorylated tau based on the Biomarker Roadmap Framework } \\
\hline \multicolumn{4}{|c|}{ Analytical validity } & \multicolumn{4}{|c|}{ Clinical validity } & \multicolumn{2}{|c|}{ Analytical utility } \\
\hline \multicolumn{2}{|c|}{$\begin{array}{l}\text { Phase } 1 \\
\text { Specimens }\end{array}$} & \multicolumn{2}{|c|}{$\begin{array}{c}\text { Phase 2: } \\
\text { Assay definitions }\end{array}$} & \multicolumn{2}{|c|}{$\begin{array}{l}\text { Phase 3: } \\
\text { Early disease detection }\end{array}$} & \multicolumn{2}{|c|}{$\begin{array}{l}\text { Phase 4: } \\
\text { Real world performance }\end{array}$} & \multicolumn{2}{|c|}{ Phase 5: Implementation } \\
\hline Primar & aim & Primary aim & Secondary aims & Primary aims & Secondary aims & Primary aim & Secondary aim & Primary aim & Secondary aims \\
\hline \multirow{2}{*}{\multicolumn{2}{|c|}{ Leads }} & \multirow{2}{*}{$\begin{array}{c}\text { Accuracy } \\
\mathrm{AD} / \mathrm{HC}\end{array}$} & Assay definition & \multirow{2}{*}{$\begin{array}{l}\text { Accuracy } \\
\mathrm{MCl} / \mathrm{HC}\end{array}$} & $\begin{array}{l}\text { Impact of } \\
\text { covariates }\end{array}$ & \multirow{4}{*}{$\begin{array}{l}\text { Correct } \\
\text { diagnosis }\end{array}$} & $\begin{array}{l}\text { Predictive } \\
\text { features }\end{array}$ & \multirow{4}{*}{$\begin{array}{l}\text { Impact on } \\
\text { outcomes }\end{array}$} & $\begin{array}{c}\text { Cost } \\
\text { assessment }\end{array}$ \\
\hline & & & $\begin{array}{l}\text { Ante mortem/ } \\
\text { autopsy }\end{array}$ & & $\begin{array}{l}\text { Compare } \\
\text { markers }\end{array}$ & & Feasibility & & $\begin{array}{l}\text { Compliance } \\
\text { across settings }\end{array}$ \\
\hline \multicolumn{3}{|c|}{ Achievement } & $\begin{array}{c}\text { Covariates in } \\
\mathrm{HC}\end{array}$ & \multirow{3}{*}{$\begin{array}{l}\text { Criteria for } \\
\text { positivity }\end{array}$} & $\begin{array}{l}\text { Combine } \\
\text { markers }\end{array}$ & & \multirow[t]{2}{*}{$\begin{array}{l}\text { Estimate impact } \\
\& \text { costs }\end{array}$} & & \multirow[t]{2}{*}{$\begin{array}{l}\text { Compare t } \\
\text { protocols }\end{array}$} \\
\hline Full & Partial & Preliminary & & & & & & & \\
\hline $\begin{array}{c}\text { Not } \\
\text { chieved }\end{array}$ & $\begin{array}{l}\text { Not } \\
\text { applicatble }\end{array}$ & Unsuccessful & Covariates in $A D$ & & Testing Interval & & $\begin{array}{l}\text { Monitor false } \\
\text { negatives }\end{array}$ & & \\
\hline
\end{tabular}

\section{b}

\begin{tabular}{|c|c|c|c|c|c|c|c|c|c|}
\hline \multicolumn{10}{|c|}{ Development of plasma amyloid- $\beta$ based on the Biomarker Roadmap Framework } \\
\hline \multicolumn{4}{|c|}{ Analytical validity } & \multicolumn{4}{|c|}{ Clinical validity } & \multicolumn{2}{|c|}{ Analytical utility } \\
\hline \multicolumn{2}{|c|}{$\begin{array}{l}\text { Phase } 1 \\
\text { Specimens }\end{array}$} & \multicolumn{2}{|c|}{$\begin{array}{c}\text { Phase } 2: \\
\text { Assay definitions }\end{array}$} & \multicolumn{2}{|c|}{$\begin{array}{c}\text { Phase 3: } \\
\text { Early disease detection }\end{array}$} & \multicolumn{2}{|c|}{$\begin{array}{c}\text { Phase } 4 \text { : } \\
\text { Real world performance }\end{array}$} & \multicolumn{2}{|c|}{ Phase 5: Implementation } \\
\hline \multicolumn{2}{|c|}{ Primary aim } & Primary aim & Secondary aims & Primary aims & Secondary aims & Primary aim & Secondary aim & Primary aim & Secondary aims \\
\hline \multirow{2}{*}{\multicolumn{2}{|c|}{ Leads }} & \multirow{2}{*}{$\begin{array}{l}\text { Accuracy } \\
\mathrm{AD} / \mathrm{HC}\end{array}$} & Assay definition & \multirow{2}{*}{$\begin{array}{l}\text { Accuracy } \\
\mathrm{MCl} / \mathrm{HC}\end{array}$} & $\begin{array}{l}\text { Impact of } \\
\text { covariates }\end{array}$ & \multirow{4}{*}{$\begin{array}{c}\text { Correct } \\
\text { diagnosis }\end{array}$} & $\begin{array}{l}\text { Predictive } \\
\text { features }\end{array}$ & \multirow{4}{*}{$\begin{array}{l}\text { Impact on } \\
\text { outcomes }\end{array}$} & $\begin{array}{c}\text { Cost } \\
\text { assessment }\end{array}$ \\
\hline & & & $\begin{array}{l}\text { Ante mortem/ } \\
\text { autopsy }\end{array}$ & & $\begin{array}{l}\text { Compare } \\
\text { markers }\end{array}$ & & Feasibility & & $\begin{array}{l}\text { Compliance } \\
\text { across settings }\end{array}$ \\
\hline \multicolumn{3}{|c|}{ Achievement } & $\begin{array}{c}\text { Covariates in } \\
\mathrm{HC}\end{array}$ & \multirow{3}{*}{$\begin{array}{l}\text { Criteria for } \\
\text { positivity }\end{array}$} & $\begin{array}{l}\text { Combine } \\
\text { markers }\end{array}$ & & $\begin{array}{l}\text { Estimate impact } \\
\& \text { costs }\end{array}$ & & $\begin{array}{l}\text { Compare t } \\
\text { protocols }\end{array}$ \\
\hline Full & Partial & Preliminary & & & & & & & \\
\hline $\begin{array}{l}\text { Not } \\
\text { Ichievec }\end{array}$ & $\begin{array}{l}\text { Not } \\
\text { applicatale }\end{array}$ & Unsuccessful & Covariates in $\mathrm{AD}$ & & Testing Interval & & $\begin{array}{l}\text { Monitor false } \\
\text { negatives }\end{array}$ & & \\
\hline
\end{tabular}

Fig. 1 A flowchart illustrating the development of blood biomarkers, p-tau (a) and A $\beta$ (b) for AD in the framework of Pepe et al. (2001). Abbreviations: $A D$, Alzheimer's disease; $H C$, healthy controls; $M C I$, mild cognitive impairment 
major constituent of neurofibrillary tangles [43] and hyperphosphorylated tau at serine and threonine amino acid residues [44], led to the development of CSF assays for A $\beta$ [45-47], t-tau [48] and p-tau [49].

The decrease in CSF A $\beta 42$ in $\mathrm{AD}$ dementia in comparison to healthy controls has been validated in numerous papers [11] and is thought to reflect sequestered of $A \beta$ in extracellular plaques. As a result, lower amounts of $A \beta$ peptides are secreted to the extracellular space, CSF and, potentially, to blood. In agreement, several papers have consistently found a high concordance between CSF A $\beta 42$ and amyloid PET status [50]. The CSF $A \beta 42 / A \beta 40$ ratio has higher performance to identify $\mathrm{AD}$ than $\mathrm{CSF} A \beta 42$ as a single biomarker. A multitude of studies also indicate that the CSF $A \beta 42 / A \beta 40$ ratio shows better concordance with amyloid PET positivity and that the CSF $A \beta 42 / A \beta 40$ ratio has a clinically relevant diagnostic value [51]. The hypothesized reasoning for this finding is that CSF $A \beta 40$ can serve as a moderator for "total" $A \beta$ levels and that the ratio with CSF $A \beta 42$ normalizes for variation in "total" $A \beta$ production level between individuals. The increase of $\mathrm{t}$-tau and $\mathrm{p}$-tau into the extracellular space is thought to reflect the intensity of neurodegeneration and NFT pathology, respectively [19]. NFTs consist of aggregated tau fragments that are phosphorylated mostly at epitopes in the far mid-region and the C-terminus [19]. P-tau fragments that are poorly retained in the NFTs (e.g. theorine181 and theorine217) are released into CSF and blood as potential biomarkers. However, despite CSF p-tau residues being specific to $\mathrm{AD}$ tau pathology, only moderate correlations exist between tau PET, an in vivo measure of NFT pathology $[52,53]$. Furthermore, soluble p-tau increase precedes tau PET by a decade [54] and emerge when $A \beta$ pathology is developing [55-58]. Thus, it has been hypothesized that p-tau release into the CSF is indicative of an active process and one that is initiated by cerebral amyloid- $\beta$ (A $\beta$ ) deposition [59]. This is further supported by the fact that MAPT mutations (e.g. R406W) resulting in NFTs consisting of combined $3 R$ and $4 R$ tau (as seen in AD) do exhibit normal CSF p-tau181 and p-tau217 levels level when $\mathrm{A} \beta$ plaques are not present [56].

CSF is continuous with the brain extracellular fluid, with a free exchange of molecules between these compartments. However, only a small proportion of brain proteins enter the bloodstream. Blood, while more accessible, is a vastly more challenging matrix to detect brain biomarkers, for several reasons: (1) low abundant brain proteins entering the blood have to be measured in a matrix containing very high levels of peripheral plasma proteins, such as albumin and IgG; and (2) brain proteins are differentially degraded by proteases in blood and metabolized in the liver or cleared by the kidneys, making the interpretation of findings difficult due high variance levels.
Prior to 2016, studies on plasma $A \beta$ failed to replicate the observed decrease in CSF - with no or only minor changes combined with large overlaps in both $\mathrm{A} \beta 42$ and $\mathrm{A} \beta 40$ between patient and control groups $[11,60]$. These disappointing early results have been attributed to the substantial contribution from peripheral tissues to the global pool of plasma $\mathrm{A} \beta$, as evidenced by the poor correlation between plasma and CSF A $\beta$ concentrations [61]. Furthermore, analytical limitations using enzyme-linked immunosorbent assay (ELISA) methods (e.g. epitope masking by hydrophobic $A \beta$ peptides binding to plasma proteins [62]) could be evaded by methodical enhancements. The high analytical sensitivity $(<1 \mathrm{pg} / \mathrm{mL})$ of the single-molecule array (Simoa) allows for predilution of samples that may reduce matrix effects. Subsequently, using this technique for $A \beta$ [63], a significantly lower plasma $\mathrm{A} \beta 42 / 40$ ratio was found in both MCI and AD cases as compared with controls $[25,64]$. Furthermore, marginally improved associations were found with CSF $A \beta$ and amyloid PET [64]. Aligned with these immunoassay efforts, immunoprecipitation mass spectrometry (IPMS) studies have attempted to evaluate whether mass spectrometric analysis could provide a more accurate quantification of $A \beta$ peptides in plasma. Pilot studies [65-67] suggested that both $A \beta 42$ and A $\beta 42 / 40$ were significantly reduced in amyloid PET-positive patients with impressive accuracies (area under curve, AUC) these studies paved the way for larger studies using mass spectrometric measures of plasma $A \beta$. These pilot findings using new generation digital immunoassays and enhanced targeted mass spectrometry rejuvenated the interest in plasma $A \beta$ for $A D$ diagnostics. The phase 1 aim is fully achieved for $A \beta$.

As mentioned above, ultrasensitive immunoassay techniques also allow for the measurement of t-tau in blood [30, 68] but are not diagnostically useful in the context of AD. Evidence from studies in acute hypoxic brain injury demonstrates a biphasic release of tau into the bloodstream that results in a primary peak of plasma t-tau during the first few hours after injury and a secondary, broader peak, that arises a few days after injury and is predictive of neurological outcome [69]. These rapid changes in plasma t-tau concentrations have also been observed in patients with concussion [70] and during anaesthesia [71], which could partially explain the lack of correlation between plasma and CSF t-tau concentrations in $\mathrm{AD}[29,72]$. Furthermore, $t$-tau is expressed in peripheral tissues and is also present in saliva with no relationship with AD pathophysiology [73, 74]. An important aspect in developing p-tau residues assays for blood was the discovery that tau fragments in blood consist mainly of N-terminal to midregion forms [59], which are different from the mid-region targeted by CSF assays [75]. Therefore, p-tau assay development for blood has focused on these species. For instance, Tatebe and colleagues [76] developed a p-tau181 assay which was modified from the Simoa t-tau assay, substituting the 
detection antibody for a p-tau181-specific monoclonal antibody. This was the first study to report significant increases of plasma p-tau181 in AD dementia and Down syndrome patients, yet still suffered from analytical sensitivity. Mielke and colleagues [77] then described an electrochemiluminescence (ECL) method, developed by Eli Lilly, to measure p-tau 181 which also reported highly significant increases in AD but importantly demonstrated a strong relationship with amyloid and tau PET. This relationship with PET - as well as with CSF measures - was later shown to become abnormal at early stages of AD pathogenesis development [78]. A method to quantify plasma and serum ptau181, more sensitive than the Simoa assay previously described, was then later developed [79]. These studies are the basis for the accumulating evidence for measuring p-tau181 by Simoa [79] and MSD [80, 81] as well as p-tau217 [82] and more recently p-tau231 [83]. The phase 1 aim is fully achieved for p-tau.

\section{Phase 2: clinical assay development for clinical disease}

The general aim of phase 2 studies is to define the ability of blood biomarker assays to discriminate $\mathrm{AD}$ dementia patients from $\mathrm{CU}$ and non-AD dementias.

\section{Phase 2: primary aim}

The primary aim of phase 2 is to estimate the true-positive rate and false-positive rate or receiver operating characteristics curve for the assays and to assess their ability to distinguish subjects with and without $\mathrm{AD}$.

Significantly lower plasma A $\beta 42 / 40$ ratios have been reported in both $\mathrm{MCI}$ and $\mathrm{AD}$ as compared with $\mathrm{CU}[64$, 84-88]. However, the primary outcome of these plasma $A \beta$ studies has predominately been to detect $A \beta$ positivity. The A $\beta 42 / 40$ ratio in plasma is reduced by $14-20 \%$ in amyloid PET-positive individuals [64, 66, 86, 87]. In comparison, a $50 \%$ reduction is observed in CSF for $A \beta 42 / 40$ [11]. As such, plasma $A \beta$ shows a greater overlap between amyloid PETpositive and amyloid PET-negative individuals. Yet, common findings are emerging between A $\beta$ IPMS studies and the fully automated $\mathrm{A} \beta$ immunoassay (Elecsys) [85]. In addition to A $\beta 42 / 40$, MS-based studies also suggest that a ratio of an APP fragment (APP669-711) to A $\beta 42$ in plasma identifies A $\beta$-positive individuals [87]. Plasma APP669-711/A $\beta 42$ ratio was $20-40 \%$ higher in $A \beta+$ individuals than in $A \beta-$ individuals, which gave high sensitivity and specificity for predicting $\mathrm{A} \beta$ status in $\mathrm{AD}$ and MCI patients, as well as in CU (91\% and 87\%, respectively) [87]. Studies comparing AD and non-AD dementias using plasma $A \beta$ assays are few. Janelidze et al. [80] demonstrated that plasma $A \beta 42 / 40$ was significantly reduced in $\mathrm{MCI} A \beta+$ when compared to $\mathrm{MCI}$
A $\beta$ - patients (which infers a non-AD pathology). Furthermore, Palmqvist et al. [82] also demonstrated that the median plasma $A \beta 42 / 40$ ratios were lower in neuropathologically confirmed $\mathrm{AD}$ when compared to non$\mathrm{AD}$ neurodegenerative diseases. The same study also demonstrates a reduction of plasma $A \beta 42 / 40$ of $A D$ dementia compared to non-AD neurodegenerative diseases in the BioFINDER cohort but was significantly inferior to other biomarkers analysed. Lin et al. [89] measured plasma A $\beta 42$ concentrations in healthy individuals and non-AD dementias. Of all the groups included in the study, dementia with Lewy bodies (DLB) had the lowest plasma A $\beta 42$ concentrations, although the reduction was not statistically significant. Individuals with frontotemporal dementia (FTD) had significantly higher blood $\mathrm{A} \beta 42$ concentrations compared to all other groups. This finding is particularly interesting given the low frequency of $A \beta$ retention in the brains of individuals with FTD [90]. There is a large agreement in the change of plasma $\mathrm{A} \beta 42 / \mathrm{A} \beta 40$ (or variations of such) in $\mathrm{AD}$ patients as compared CU A $\beta$ - controls, which are seemingly more promising for mass spectrometric methodologies than immunoassays. However, there are limited dedicated studies on the performance of $A \beta$ assays in non-AD dementias. The primary aim of phase 2 is thus only partially achieved for $A \beta$.

A breakthrough discovery in the mid-1990s demonstrated that AD patients had increased levels of CSF p-tau, which was not found in other neurological diseases [48]. Later studies have since confirmed that CSF p-tau181 can be used to differentiate $\mathrm{AD}$ from other dementias, such as frontotemporal dementia (FTD) and dementia with Lewy bodies [91-93]. Recently, five studies have shown that CSF p-tau217 perform somewhat better than CSF p-tau181 when differentiating AD from non-AD diseases [92-96]. These findings have now been largely replicated using blood p-tau. P-tau 181 has been quantified using both the Simoa $[79,97,98]$ and MSD platforms $[80,81]$ which utilizes different antibodies. Janelidize et al. described high accuracy (AUC $=0.93$, sensitivity $=0.92$, specificity $=0.87$ ) in detecting $\mathrm{AD}$ from non-AD neurodegenerative disorders [80] which was comparable to CSF measures of A $\beta$ and t-tau and only slightly inferior to CSF p-tau181 and tau PET. Similarly, Karikari et al. [79] demonstrated a complete separation between AD and FTD patients. In the replication cohort, the high accuracies also observed in distinguishing between $\mathrm{AD}$ and non- $\mathrm{AD}$, however, demonstrated more variability, which was dependant on the non$\mathrm{AD}$ diagnosis (vascular dementia, $\mathrm{AUC}=0.92$; atypical parkinsonian disorders, $\mathrm{AUC}=0.89$; behavioural FTD and Parkinson disease, AUC < 0.85). Furthermore, high accuracy in differentiating $\mathrm{AD}$ from FTLD patients has been observed in two other studies using serum [97] or plasma [81] p-tau181. A recent publication showed that plasma p-tau217 discriminates clinically diagnosed $\mathrm{AD}$ from non-AD dementias with the same accuracy as CSF p-tau217 and tau PET imaging (all 
with AUCs > 0.95), and the levels in the plasma of p-tau217 are 5-7-fold increased in AD dementia compared to other neurodegenerative diseases [82]. The usefulness of plasma p-tau217 was supported by a recent mass spectrometrybased study [99].

Plasma p-tau181 and p-tau217 have been validated in longitudinal studies using ante-mortem collected blood samples and post-mortem histopathology. In the paper by Palmqvist et al. [82], plasma p-tau217 could detect cases with a high likelihood of $\mathrm{AD}$ according to the NIA-Regan criteria with an AUC of 0.98 [82]. Similarly, high performance was found in a study using plasma p-tau181 [98]. The primary aim of phase 2 is fully achieved for $\mathrm{p}$-tau.

\section{Phase 2: secondary aim 1}

The secondary aim 1 of phase 2 addresses the optimization of the operating procedures and assessment of the reproducibility of the assay within and between laboratories. A large amount of work has been published on the preanalytical factors of CSF biomarkers. These advancements have been highlighted as the most important achievements in the updated Biomarker Roadmap for CSF biomarkers [10] - however, at this time, a limited amount of published data on assay comparisons and preanalytical parameters have been reported for blood biomarkers. Yet, a general guideline for blood biomarkers research has been published [100].

The first effort in comparing analytical methods for $A \beta$ has been achieved by the GBSC; as presented at Alzheimer's Association International Conference 2019, identical aliquots of 81 EDTA plasma samples were sent to 11 laboratories and analysed using standard immunoassays (ELISA, Simoa and Elecsys) or immunoprecipitation mass spectrometry (IPMS) methods. Correlations of A $\beta 42$ concentrations were absent or weak (standard immunoassays) or moderately strong (IPMS methods), while A $\beta 40$ offered more consistency. Clearly, additional assay harmonization and standardization work are required. A recent report [101] has investigated the preanalytical variables of the Elecsys $A \beta 42$ and $A \beta 40$ quantification which showed that these biomarkers were not affected by up to three freeze/thaw cycles, five tube transfers or the size of a collection tube. The same study demonstrated a small diurnal variability for plasma $A \beta 42$ and $A \beta 40$ but no effect was observed for the $A \beta 42 / A \beta 40$ ratio. Compared to EDTA plasma, an increase and decrease of $\mathrm{A} \beta$ biomarkers was observed for lithium heparin and sodium citrate, respectively. Finally, $\mathrm{A} \beta$ was stable up to $6 \mathrm{~h}$ at $+4{ }^{\circ} \mathrm{C}$ but only $1 \mathrm{~h}$ at room temperature. Partial evidence exists for phase 2 secondary 1 for $\mathrm{A} \beta$.

To date, no intra-laboratory comparison of the most widely reported p-tau assays from the University of Gothenburg [79] and Eli Lilly $[77,82]$ has been published. The methodology for the Simoa assay has been fully reported [79] and has been successfully transferred to a commercially validated assay by Quanterix, offering an indirect verification of the method. We are also aware that $\mathrm{p}$-tau values in serum are lower than for plasma [79] and that multiple freeze-thaws may effect $p$-tau values (Ashton et al., Alzheimers Dement (Amst), accepted). No reports on how p-tau can be affected by operatorinfluenced preanalytical variables have been published but is an ongoing aim by the Global Biomarker Standardization Consortium (GBSC). There is only preliminary evidence for phase 2 secondary 1 for $\mathrm{p}$-tau.

\section{Phase 2: secondary aim 2}

The secondary aim 2 of phase 2 is to determine the relationship between biomarker tissue measurements made on brain tissue and the biomarker measurements made on the noninvasive clinical specimen (e.g. blood).

Investigations examining the relationship between plasma $A \beta$ and neuropathologically confirmed cases are limited. As previously mentioned, Palmqvist et al. [82] demonstrated marginal changes between neuropathologically confirmed $\mathrm{AD}$ and non- $\mathrm{AD}$ cases using $\mathrm{A} \beta$ assays. The lack of studies comparing these modalities may be due to the unconvincing correlations between plasma $\mathrm{A} \beta$ and cerebral $\mathrm{A} \beta[64,85$, $102]$, the large volumes $(250-1000 \mathrm{uL})$ required for IPMS studies [86, 87], propriety immunoassay technologies [85] or simply that recent evidence demonstrates that plasma $\mathrm{p}$-tau demonstrates a stronger relationship with in vivo $A \beta$ than plasma $A \beta$ itself $[79-81,85]$. Nonetheless, plasma $A \beta$ has shown consistent utility in separating $A \beta+$ and $A \beta$ - individuals determined by PET. For IPMS studies, the AUC for $A \beta 42$ ranges from $72-87 \%[67,87]$, between $80-97 \%$ for $\mathrm{A} \beta 42 / \mathrm{A} \beta 40[66,67,86,87]$ and between $82-97 \%$ for the APP669-711/A $\beta 42[67,87]$. In contrast, accuracies of between $60-64 \%$ and $62-68 \%$ have been reported for the commercially available Simoa assays [25, 64, 103], although higher AUCs were achieved for a modified version of the Simoa assay which utilized differing antibodies [102]. Plasma $A \beta 42 / A \beta 40$ measured by the fully automated Elecsys assay predicts $A \beta$ status with an accuracy $>80 \%$ [85]. No in vivo $A \beta$ prediction has been reported for IMR [68], MSD [104] or plasma exosome-bound A $\beta 42$ (APEX) [105]. Interestingly, plasma biomarkers (both $A \beta$ and $p$-tau) have already been shown to significantly change approximately at the same point as the corresponding CSF biomarkers [78]. The secondary aim of phase 2 is partially achieved for $\mathrm{A} \beta$.

To date, there have been five studies that have addressed the relationship between plasma $p$-tau measurements and post-mortem data. All studies confirmed that plasma $p$-tau could separate AD pathology from non-AD pathology with high accuracy [80-83, 98]. It was reported that plasma ptau217 had a high accuracy in predicting AD pathology from 
non-AD pathology and demonstrated a strong relationship between p-tau217 and NFT density score in AD - which was not observed for non-AD [82]. Lantero Rodriguez et al. [98] demonstrated that plasma p-tau181 predicts AD pathology at least 8 years prior to neuropathological confirmation and increased with severity of Braak staging. This study also confirmed that longitudinal increases are attributed to NFT pathology which plateaus at end-stage disease. As previously mentioned, several studies have now emerged that plasma $\mathrm{p}$ tau correlates strongly with $\mathrm{A} \beta$ and tau pathology in $\mathrm{AD}$ [77-82, 106, 107] but plasma p-tau and CSF p-tau only correlate in the presence of $A \beta$ pathology. In support of this, plasma p-tau is seen to be increased in Braak 0 patients (e.g. tau PET-negative) if $A \beta$ is already present [79]. Therefore, plasma $p$-tau is sensitive to both $A \beta$ and tau pathologies but begins to increase in response to or concurrently with $A \beta$. All findings demonstrated by CSF p-tau $[9,10]$ have been replicated in blood, corroborating that p-tau is a robust blood biomarker for AD pathology. The secondary aim of phase 2 is fully achieved for $\mathrm{p}$-tau.

\section{Phase 2: secondary aim 3 and secondary aim 4}

The secondary aims 3 and 4 of phase 2 are to assess covariates (e.g. sex, age) associated with biomarker status or level in CU (secondary aim 3 ) and disease (secondary aim 4) subjects. If there is an effect on the biomarker, these covariates may be considered when defining thresholds for positivity in each concerned subpopulation. The effect of demographic factors on blood biomarkers in CU participants or disease patients has not been studied in detail but has been reported as part of the description the biomarker performance in various studies. Increasing age and $A P O E \& 4$ carriership are associated with $\mathrm{AD}$ [108]; as such, blood AD-related biomarkers are more commonly affected in disease groups.

No sex differences in CSF A $\beta 42$ concentrations have been found for any disease stage or APOE genotype [109], and therefore we may expect the same relationship to exist for plasma A $\beta$. Schlinder et al. [86], however, described that plasma A $\beta 42 / 40$ decreased significantly in males and $A P O E$ $\varepsilon 4$ carriers. Palmqvist et al. [85] reported no age effect of $A \beta$ levels in all diagnostic categories and also demonstrated that the prediction of $\mathrm{A} \beta$ positivity did not differ in younger $(<$ 72 years) as compared to older ( $>73$ years). In contrast, older age was assocaited to a decrease of plasma $A \beta 42 / 40$ and was a significant contributor to the prediction of $A \beta+$ in IPMS A $\beta$ studies [86]. This finding was also found in an earlier report [110], but how these disparities are influenced by assay differences is not known. For $\mathrm{A} \beta$, preliminary evidence exists for secondary aims 3 and 4 in phase 2 .

In some p-tau studies, demographic factors were included in a linear regression model, suggesting an incidental effect on the biomarker performance, but were not individually reported. Karikari et al. [79] and Ashton et al. [83] presented data from young $\mathrm{CU}$ individuals ( $<40$ years) and demonstrated a significant reduction as compared to CU elderly adults without amyloid pathology ( $>65$ years) in p-tau181 and ptau231, respectively. Further, Tatebe et al. [76] demonstrated a positive correlation between age and $p$-tau 181 in individuals with Down syndrome, with weak correlations reported by Lantero Rodriguez et al. $(r=0.25-0.30)$ [98] and no relationship reported by Thijssen et al. [81]. This does suggest that age may have a minor influence on the concentrations of $p$-tau, but to what degree this is independent of undetectable accumulating cerebral $A \beta$ is unclear. Plasma $p$-tau 217 has been studied in autosomal-dominant $\mathrm{AD}$ [82], where a positive correlation with age was only observed in mutation carriers. In agedmatched non-carriers, no correlation between age and p-tau was observed which is in line with CSF p-tau associations with age [111]. This highly suggests that a correlation between age and $p$-tau is dependent on $A \beta$ pathology. Thus far, no significant reports of sex differences have been reported $[81,98]$. For $p$-tau, preliminary evidence exists for secondary aims 3 and 4 in phase 2 .

\section{Phase 3: longitudinal repository studies}

The general aim of phase 3 studies is to define the ability of the biomarker to detect the disease in its early phase, e.g. MCI in the context of the Biomarker Roadmap.

\section{Phase 3: primary aim 1}

The primary aim 1 of phase 3 is to evaluate the capacity of the biomarker to predict the subsequent development of $\mathrm{AD}$ dementia in patients with mild cognitive impairment.

While minimal data is available for the future risk of dementia with $A \beta$ measures, Janelidze et al. [80] have demonstrated no association of $A \beta 42 / 40$ and increased risk ( $\mathrm{HR}=$ $0.8195 \% \mathrm{CI}=0.64-1.02)$. Using longitudinal cognition (MMSE) and conversion to AD dementia as outcomes in MCI patients, Cullen et al. [112] showed a model combining plasma p-tau 181 and NfL, but not $\mathrm{A} \beta 42 / \mathrm{A} \beta 40$ (Elecsys assay), had the best prognosis performance of all models. Moreover, this finding held when performing a sensitivity analysis using $A \beta 42 / A \beta 40$ from a mass spectrometry assay (Araclon Biotech Ltd). Verbeck et al. [102], while they did not perform a future risk analysis, showed that $A \beta$ were less associated to cognitive domains than plasma GFAp and NfL. Conversely, using IPMS A $\beta$ measures, individuals with negative amyloid PET scans at baseline but a positive plasma A $\beta 42 / A \beta 40$ had a 15 -fold greater risk of conversion to amyloid PET positivity [86], which could be valuable for therapeutic trial recruitment.

Plasma p-tau181 and p-tau217 are increased at the MCI stage, if $A \beta$ is present $[77,79,80,82,106,107]$. The increase 
from $\mathrm{A} \beta+\mathrm{MCI}$ to $\mathrm{AD}$ dementia is much less pronounced, however, and in most cases is nonsignificant. However, a larger increase from $\mathrm{A} \beta+\mathrm{MCI}$ to $\mathrm{AD}$ dementia is observed for $\mathrm{p}$-tau 217 [82]. If $A \beta$ is not determined, the differences between CU and MCI remain significant but with larger overlaps and the interpretation becomes much less clear [25, 79, $98,107]$. It also must be noted that plasma p-tau significantly increases in preclinical $\mathrm{AD}$ (e.g. $\mathrm{A} \beta+\mathrm{CU})$. Plasma p-tau 181 has been shown to have an accuracy of between 70 and $82 \%$ for predicting $A \beta$ status at the $\mathrm{CU}$ stage $[75,79,80,82]$ whereas plasma p-tau217 is significantly higher $(>90 \%)$ [82]. Plasma p-tau at baseline is a strong predictor of progression to cognitive decline which is seen to be comparable to CSF p-tau [79, 80, 107]. In the study by Janelidze et al., [80] it was found that individuals who had abnormal baseline levels of p-tau181 had a substantially increased risk of developing $\mathrm{AD}$ dementia in the future $(\mathrm{HR}=10.9,95 \% \mathrm{CI}=5.0-24.0)$. In a similar manner, using the ADNI data resource [113], higher plasma p-tau181 in MCI patients $(\mathrm{HR}=22.75,95 \% \mathrm{CI}=$ 9.90-52.3) and $\mathrm{A} \beta+\mathrm{CU}$ individuals $(\mathrm{HR}=3.25,95 \% \mathrm{CI}=$ 1.12-9.40) had a greater risk of developing $\mathrm{AD}$ dementia over a 48-month period. The hazard ratios (HR) observed for plasma where similar for CSF results from the same patients (MCI, HR = 37.1, 95\% CI $=15.0-91.8 ; \mathrm{HR} \mathrm{A} \beta+\mathrm{CU}=5.4$, $95 \% \mathrm{CI}=1.8-16.3$ ) [79]. In a follow-up study, we have found that plasma p-tau181, together with plasma NfL, can be used for individualized risk prediction of conversion to $\mathrm{AD}$ dementia at 4 years of follow-up in patients with MCI in both the BioFINDER and ADNI studies [112]. To facilitate the use of these plasma-based models, the markers were incorporated into an online tool that can be used for individualized prognosis in MCI (www.predictprogression.com). Phase 3 primary aim 1 is fully achieved for $\mathrm{p}$-tau.

\section{Phase 3: primary aim 2}

The primary aim 2 of phase 3 is to define criteria for a positive biomarker test in preparation for phase 4 . As stated by Leuzy et al. [10], a variety of statistical approaches have been proposed to dichotomize continuous $\mathrm{AD}$ biomarkers as normal or abnormal. In clinical chemistry, biomarker cut-offs are commonly defined as the $95 \%$ confidence interval in people without disease - as proposed for plasma NfL [27]. So far, a small number of studies have reported concentration cut-offs based on the maximum of accuracy for the target or choosing a cutpoint that yields a predefined level of sensitivity or specificity.

Elecsys $A \beta 42 / A \beta 40$ cut-off of 0.065 was validated in an independent sample with similar AUCs [85]. Further, estimates from a linear regression model that incorporated $A \beta 42$ and $A \beta 40$ as separate measures resulted in higher AUCs in the validated cohort $(\mathrm{AUC}=0.86)$. In applying the regression model of $\mathrm{A} \beta 42, \mathrm{~A} \beta 40$ and $A P O E$, it was shown that PET costs could be reduced by approximately
$1 / 3$ in a typical trial design for $A \beta$ therapeutics. In IPMS methods, a plasma $A \beta 42 / A \beta 40$ cut-off of $<0.1218$ was reported for $\mathrm{A} \beta$ PET-positive individuals, with a positive predictive value of 0.88 (95\% CI $0.75-0.96)$ and a negative predictive value of 0.76 (95\% CI $0.67-0.83$ ) [86]. An impressive concordance of plasma and CSF A $\beta 42 / A \beta 40$ (84\%) was reported if these cut-offs were applied in an independent sample. In an earlier discovery study, employing the same technique, an optimal cut-off value of $<0.1243$ of the plasma $A \beta 42 / A \beta 40$ concentration ratio was reported [66]. This highlights the robust measurement of $A \beta 42$ and $A \beta 40$ across studies, using both automated immunoassay and mass spectrometric techniques. Thus, efforts have been made to report cut-off for various $A \beta$ assays; however, these cut-offs have not been tested fully by independent laboratories. Preliminary evidence exists for $A \beta$ in phase 3 primary aim 2 .

Karikari et al. [79] estimated a cut-off of $15.9 \mathrm{pg} / \mathrm{ml}$ for p-tau181 from a small discovery cohort $(n=37)$ which performed favourably in the TRIAD $(n=226)$ and BioFINDER $(n=763)$ validation cohorts. This cutoff was also applicable to independent cohorts in subsequent publications [97, 98, 114]. In the ADNI multicenter study [80], which utilized the same Simoa platform, a cut-off of $17.7 \mathrm{pg} / \mathrm{ml}$ for AD diagnosis $(14.5 \mathrm{pg} / \mathrm{mL}$ for $A \beta$ positivity) was reported which is comparable to the previous cut-off generated from a small sample set. This analysis in ADNI indeed demonstrated a substantial estimated cost-saving if applied in a therapeutic trial recruitment strategy for preclinical AD [107]. These findings support the robustness of the Simoa assay and plasma p-tau181 as a biomarker for routine use across clinical settings and laboratories. It is important, however, to understand that these cut-offs cannot be translated to other p-tau assay platforms. For example, on the MSD platform, Janelidze et al. [80] reported a cut-off of $1.81 \mathrm{pg} / \mathrm{mL}$, for differentiation for a future conversation to AD dementia, while Thijsen et al. [81] reported $8.4 \mathrm{pg} / \mathrm{mL}$ for $\mathrm{A} \beta$ positivity. Although these are not the same diagnostic parameters as described for Simoa assay studies above, it demonstrates the discrepancies in relative biomarker concentrations reported across these assays and potentially, across cohorts. Preliminary evidence exists for $\mathrm{p}$-tau in phase 3 primary aim 2 .

\section{Phase 3: secondary aim 1}

The secondary aim 1 of phase 3 is to explore the impact of covariates on the discriminatory abilities of the biomarker in the early disease phase. This aim is not achieved for either $p$ tau or $\mathrm{A} \beta$. Using CSF biomarkers as reference, no adjustment for age, sex or APOE $\varepsilon 4$ allele has been recommended [10] but this cannot be confirmed for blood biomarkers as of yet. 


\section{Phase 3: secondary aim 2}

The secondary aim 2 of phase 3 is to compare the different biomarkers available in order to select the most promising ones.

In p-tau studies where other biomarkers have been compared, p-tau alone was deemed the best predictor of $\mathrm{AD}[25$, $79,80,82]$. Yet, the combination of $A \beta 42 / A \beta 40$ with $p$-tau may have a slight improvement in predicting $A \beta$ status [80]. Ratios of $\mathrm{p}$-tau with plasma $\mathrm{A} \beta 42$ or t-tau also do not improve diagnostic accuracy [82].

As stated earlier, in most instances, $A \beta 42 / A \beta 40$ outperforms $A \beta 42$ alone, and Nakamura et al. [87] described the APP669-711/A $\beta 42$ ratio being superior to both. In other IPMS studies, Schindler et al. described the superiority of plasma $\mathrm{A} \beta 42 / \mathrm{A} \beta 40$ combined with age and $A P O E \varepsilon 4$ status [86]. Employing the automated Elecsys platform, Palmqvist et al. [85] demonstrated the improvement of plasma A $\beta 42 / A \beta 40$ from 80 to $86 \%$ accuracy if combined with plasma t-tau, plasma NfL and $A P O E$ status. A recent study by Verberk et al. [102] showed that the combination of plasma $\mathrm{A} \beta 42 / \mathrm{A} \beta 40$ and GFAp provides a superior prediction of any biomarker alone - however, p-tau was not included in this study. The correlations between plasma and CSF levels of $A \beta 42$ and $A \beta 40$ were poor in these studies, further supporting that a peripheral production of $A \beta$ is a confounder. Phase 3 secondary aim 2 is partially achieved for plasma $A \beta$ and $\mathrm{p}$-tau but the superior assays in both modalities (e.g. IPMS $\mathrm{A} \beta$ and $\mathrm{p}$-tau) have yet to be combined in disease cohorts.

\section{Phase 3: secondary aim 3}

The secondary aim 3 of phase 3 is to develop algorithms for the biomarker-based diagnosis of MCI in preparation of phase 4. Several studies have explored whether the detection of prodromal AD can be improved by combining CSF AD biomarkers with neuroimaging [10]. However, the context of use and main advantage of blood biomarker is its wide-scale accessibility. It is unlikely that a blood biomarker will outperform CSF and will be better placed as a triage tool for further investigations. Therefore, it is counterintuitive to combine blood with CSF/PET in a prediction model. It is conceivable to combine cognitive tests or simple MRI measures with blood biomarkers, and this would relate to a different context of use than a diagnosis in memory clinics, such as screening in the population or case finding in primary care contexts. Combining plasma $\mathrm{A} \beta 42 / \mathrm{A} \beta 40$, p-tau 181 and $\mathrm{NfL}$ in patients with MCI from BioFINDER and ADNI, Cullen et al. [57] compared the prognostic ability of plasma biomarkers to the same biomarkers measured in CSF, as well as to a more basic model comprising age, sex, education and baseline MMSE. Using cognitive decline and progression to AD dementia over 4 years as outcomes, the authors calculated risk probabilities at the individual patient level using linear regression combined with internal and external validation analyses. Plasmabased models were, overall, non-inferior or better than CSFbased models and superior to the basic model. As mentioned above, these prediction models were also incorporated into an online tool (www.predictprogression.com) providing individualized risk estimates in MCI. Preliminary evidence exists for $\mathrm{p}$-tau for phase 3 secondary aim 3 , while this aim remains is not achieved for $A \beta$.

\section{Phase 3: secondary aim 4}

The secondary aim 4 of phase 3 is to determine a biomarker testing interval for phase 4 if repeated testing is of interest. Longitudinal measurements of plasma p-tau have revealed low intra-individual variability, which could be of potential benefit in disease-modifying trials seeking a measurable response to a therapeutic target $[25,98,106,113]$. However, the stability of p-tau has not been common in all studies, namely in the longitudinal evaluation of familial AD [114], which may reflect different preanalytical protocols or a difference in how p-tau is expressed in familial AD. This aim is not achieved.

\section{Discussion}

In this review, we aimed to assess the maturity of blood biomarkers for $\mathrm{AD}$, $\mathrm{p}$-tau and $\mathrm{A} \beta$, according to an oncologybased validation framework adapted for use with AD biomarkers [1, 3]. The validation status for CSF was included in 2017 [9] and has been updated in this edition [10].

Plasma p-tau (p-tau181 and p-tau217) and $A \beta(A \beta 42 / A \beta$ ratios) were selected for their direct application for $\mathrm{AD}$ (phase 1). However, while CSF t-tau is considered in the CSF framework, plasma t-tau was omitted due to the previously published evidence demonstrating limited validity as an AD biomarker $[25,29,30,115]$. Furthermore, while plasma NfL is the most published blood biomarker related to $\mathrm{AD}$, it was also not considered due to its global association to neurodegeneration [26, 27] and neurological injury [28, 116] (e.g. nonspecificity for AD). Furthermore, the recent development of GFAp as an AD biomarker [25, 102, 107] has not been considered.

There is sufficient evidence that plasma p-tau fulfils the criteria for full achievement in identifying AD (phase 2; primary aim 1), early disease (phase 3 ; primary aim 1) and has tissue-biofluid association (phase 2; secondary aim 2). The performance of $\mathrm{p}$-tau in these categories is highly impressive, with the prediction of diagnostic groups and dichotomized pathology status comparable to in vivo CSF and PET measures. Furthermore, baseline increases of p-tau biomarkers are strong predictors of disease progression, performing similarly to CSF p-tau181. To date, there have been twelve independent 
data reports on plasma p-tau181 and two on plasma p-tau217. Yet, the limited evidence available may suggest some superiority of plasma p-tau217 over plasma p-tau181 [82], which is in line with CSF comparisons of the same biomarkers [92, 93, 117]. However, a biomarker comparison using the same detector antibody in sandwich immunoassay format has yet to be performed, and therefore it cannot be determined if the observed superiority is either assay or epitope dependent. It must be noted that the advantage of p-tau217 over p-tau181 has been demonstrated using mass spectrometry [99]. One recent report examines p-tau231 in blood [83] and suggests that while there is no diagnostic advantage over p-tau181, ptau231 increases early in preclinical disease. Plasma $A \beta 42 / A \beta 40$, which is superior to plasma $A \beta 42$, only has achieved partial fulfilment for the same criteria fully achieved by $\mathrm{p}$-tau. Although impressive accuracies have been described for IPMS and Elecsys methods, the complexity and availability of platforms have limited their investigation in larger and multiple independent cohorts.

In summary, p-tau demonstrates two clear advantages over $\mathrm{A} \beta$, which have immediate clinical application. Firstly, p-tau has been robustly shown to identify $\mathrm{AD}$ in cases with dementia - with non-AD dementias having levels similar to PET A $\beta$ controls. These findings have already been widely replicated and validated in numerous neuropathological cohorts. This opens the possibility of routinely using plasma p-tau to improve the confidence in an AD diagnosis in primary care and administering symptomatic treatment (e.g. acetylcholinesterase inhibitors or memantine). Importantly, a "negative" plasma p-tau measure, in the presence of cognitive deficit, would highlight the requirement of further examination of suspected non- $\mathrm{AD}$ dementia (e.g. structural MRI, DAT scans, FDG-PET) without delay. Secondly, plasma p-tau (or p-tau-based models) highlights the future risk of dementia to the same degree as CSF biomarkers. This would be a rapid indication of those at greater risk, informing on patient management and administering disease-modifying drugs once available. At this time, $A \beta$ measures have not shown to have these clinical capabilities; however, plasma $A \beta$ may have utility in highlighting the risk of future $A \beta$ deposition and contribute to an accurate prediction model of preclinical AD.

While $p$-tau, and to a lesser degree $A \beta$, has rapidly achieved success, they are lacking in assay comparisons (phase 2; secondary aim 1). Cut-offs derived for immunoassay and IPMS measures of $p$-tau and $\mathrm{A} \beta$ have achieved replication (or similar cut-off values) in validation studies but across laboratory comparisons are currently not available. Furthermore, detailed descriptions of the impact of covariates in healthy ageing (phase 2; secondary aim 3 ) and disease (phase 2; secondary aim 4) are lacking. This is where the biggest improvement has been achieved for CSF biomarkers [10]. The optimization of operating procedures and assay reproducibility is now fully achieved with a protocol for the handling of CSF AD biomarkers [118].
Furthermore, phase 3 is also fully complete for CSF biomarkers, which has allowed for reported criteria on positivity and preliminary evidence for phase 4 which aims to support the feasibility of the widespread use of CSF AD biomarkers. Though plasma biomarkers have yet to achieve the same feat, this is likely to be fully investigated soon given the relative ease and acceptance of venipuncture. A key and often overlooked aspect to fluid biomarker assessment, which remains an issue in CSF biomarkers [10], is the assessment of AD blood biomarkers in more diverse ethnic groups. Recently, however, some progress has been achieved in this area for plasma t-tau, plasma NfL and plasma GFAp [119].

In order to understand AD biomarkers in blood, it is important to understand what an immunoassay or mass spectrometric technique is capturing and what it represents. CSF ptau181 (and other p-tau variants) is often thought to be a measure of all forms of tau phosphorylated at this epitope in CSF. However, this may not be correct. The clinically approved CSF p-tau181 tests (from commercial vendors including Elecsys ${ }^{\circledR}$, Innotest ${ }^{\circledR}$ and Lumipulse $($ ) target mid-region forms of tau phosphorylated at threonine 181 [120-122]. These assays follow the principle of sandwich ELISA: a capture antibody specific to the threonine-181 phosphorylation site partnered with an antibody that binds nonphosphorylated tau at the mid-region of the protein. This means that the CSF p-tau181 assays measure phosphorylated forms of tau metabolized from the soluble pool of brainderived tau that contain the mid-region part of the protein. We now know that CSF contains both N-terminal and midregion tau in highly measurable quantities $[59,123]$. In comparison, C-terminal tau forms are poorly secreted into CSF $[124,125]$. On the other hand, evidence has emerged that blood may be predominately consisting of N-terminal to mid-region forms of tau. Consequently, the development of p-tau assays for blood has focused on these species. Tatebe et al. [76] developed a p-tau181 assay by substituting the detection antibody in the Simoa ${ }^{\mathrm{TM}}$ Tau 2.0 total tau kit for a p-tau181-specific monoclonal antibody. Karikari et al. [79, 93] developed novel p-tau 181 and p-tau 217 assays targeting p-tau forms that also contain the $\mathrm{N}$-terminal amino acid 6-18 epitope. Similarly, the Eli Lilly-developed p-tau181 and ptau217 are located N-terminally to the p-tau sites [56]. Although each of the assays was primarily developed for use in blood, they are equally suitable for use in $\operatorname{CSF}[75,92,93]$. By contrast, a p-tau assay that uses the same phosphorylationspecific antibody for both capture and detection (IMR method) thus exclusively targeting phosphorylation at threonine181 irrespective of the fragment(s) on which this occurs [126] is increased not only in $\mathrm{AD}$ but also in other neurogenerative disorders [89]. Plasma $A \beta 42, A \beta 40$ and other $A \beta$ peptides are proteolytic products of the amyloid precursor protein [127]. Plasma $A \beta$ peptides are thought to be metabolic byproducts of brain-derived extracellular amyloid plaques, 
although considerable peripheral sources of $A \beta$ have been reported thereby reducing the specificity of plasma $A \beta$ measures as biomarkers for brain pathophysiology compared to CSF A $\beta$ [128]. Plasma A $\beta$ assays include ELISA-based immunoassays on the Simoa [64], Elecsys [85] and IMR [129] platforms as well as IPMS assays $[65,66,86,130]$. The IPMS assays involve enrichment of $A \beta$ in plasma by immunoprecipitating with $A \beta$ antibodies, either mid-region $[66,87]$ or N-terminal [65] coated onto paramagnetic beads. Stable isotope-labelled synthetic peptides corresponding to each $A \beta$ peptide of interest (e.g. $A \beta 42, A \beta 40$ and $A \beta 38$ ) are used as mass spectrometry quantification standards. However, in the case of the Nakamura et al. [87], A $\beta 38$ is used as a single standard for all $\mathrm{A} \beta$ forms of interest.

This review recognizes some important limitations. The rating of phases and aims are, in some instances, based on limited studies from the same research group(s), which may introduce bias into our conclusions without independent findings. The online supplement clearly stipulates the studies evaluated in this review to provide clarity for the reader, however. In addition, the diagnosis of $\mathrm{AD}$ and $\mathrm{MCI}$ varied across studies (AD dementia; in vivo PET; neuropathological) as the standard of truth (e.g. post-mortem diagnosis) could not be applied to all studies. However, given the nature of current blood biomarker research, the majority of studies had at least one measure of cerebral A $\beta$ pathology by either CSF or PET. Further, given the known association between CSF/PET neuropathological findings at postmortem [131-133], we feel this is an adequate and more feasible assessment of than post-mortem diagnosis, particularly since this review focused on $\mathrm{AD}$ at the prodromal (i.e. $\mathrm{MCI}$ ) stage where the interval between blood and post-mortem assessment would be considerable. We also recognize at the time of the review recent data on plasma p-tau 231 could be included in the evaluation [83] despite being sporadically mentioned. A further limitation is that while we aimed to be as inclusive as possible when reviewing the literature, our search was not conducted as a formal systematic review. A number of PubMed research strings were proposed by the Biomarker Roadmap Initiative and adapted for individual projects; however, the literature databases and some selection criteria for included papers were chosen by the authors of each review, who could add papers from personal knowledge (e.g. preprints). Finally, in this review, we have assumed the same context of use adopted from 2017 by the Strategic Biomarker Roadmap, e.g. diagnosis in specialistic centres. However, the potential and the specific features of plasma biomarkers may require to validate and assess them considering screening and case finding as the proper contexts of use.

\section{Conclusion}

In this review, we have assessed that stage of maturity of blood AD biomarkers ( $p$-tau and $A \beta$ ) in context of the
Biomarker Roadmap Initiative. Owing to the experience on fluid assessment built with CSF biomarkers, much has been achieved in a short period of time. Full achievements for p-tau have been obtained in phases 1 to 3 , with partial achievement for $\mathrm{A} \beta$. Plasma p-tau (p-tau217 and p-tau181) highlights AD in dementia cases with high accuracy and is validated by neuropathological studies. Plasma $\mathrm{p}$-tau also can highlight future $\mathrm{AD}$ risk, which is comparable to CSF p-tau181 risk models. However, the field of blood biomarkers is undoubtedly lacking assay platform comparisons, clear preanalytical guidance and the effect of common covariates on biomarker levels which will inform on accurate biomarker cut-offs. More information is needed on these secondary aims in phases 2 and 3 before phase 4 (real-world performance) and phase 5 (assessment of impact/cost) studies can be initiated for blood biomarkers.

Funding Open access funding provided by University of Gothenburg. Work at the authors' research centre was supported by the European Research Council, the Swedish Research Council, the Knut and Alice Wallenberg Foundation, the Marianne and Marcus Wallenberg Foundation, the Strategic Research Area MultiPark (Multidisciplinary Research in Parkinson Disease) at Lund University, the Swedish Alzheimer Foundation, the Swedish Brain Foundation, the Parkinson Foundation of Sweden, the Parkinson Research Foundation, the SkåneUniversity Hospital Foundation, the Bundy Academy, the Swedish federal government under the Agreement for Medical Education and Research and the Alzheimer Drug Discovery Foundation (ADDF). VG reports grants from the Swiss National Science Foundation (projects 320030_169876 and 320030_185028). This work was supported by the Swiss National Science Foundation (grant n. IZSEZ0_188355), by the Alzheimer's Association, by the OsiriX Foundation and by the APRA (Association Suisse pour la Recherche sur l'Alzheimer).

Data availability https://drive.switch.ch/index.php/s/ 4reUTSuqNZHyIC8

Code availability Not applicable.

\section{Declarations}

Ethical approval This article does not contain any studies with human participants or animals performed by any of the authors.

Consent to participate Not applicable.

Consent to publication Not applicable.

Conflict of interest HZ has served at scientific advisory boards for Denali, Roche Diagnostics, Wave, Samumed, Siemens Healthineers, Pinteon Therapeutics and $\operatorname{CogRx}$; has given lectures in symposia sponsored by Fujirebio, Alzecure and Biogen; and is a co-founder of Brain Biomarker Solutions in Gothenburg AB (BBS), which is a part of the GU Ventures Incubator Program. KB has served as a consultant, at advisory boards, or at data monitoring committees for Abcam, Axon, Biogen, JOMDD/Shimadzu, Julius Clinical, Lilly, MagQu, Novartis, Roche Diagnostics and Siemens Healthineers and is a co-founder of Brain Biomarker Solutions in Gothenburg AB (BBS), which is a part of the 
GU Ventures Incubator Program. OH has acquired research support (for the institution) from AVID Radiopharmaceuticals, Biogen, Eli Lilly, Eisai, GE Healthcare, Pfizer and Roche. In the past 2 years, he has received consultancy/speaker fees from AC Immune, Alzpath, Biogen, Cerveau and Roche. VG received financial support for research through her institution from Siemens Healthineers, GE Healthcare, Life Molecular Imaging, Cerveau Technologies, Roche, Merck and consultancy/speaker fees from Siemens Healthineers and GE Healthcare. NJA, AL, TKK, $\mathrm{NMC}, \mathrm{AD}, \mathrm{MB}, \mathrm{CJ}$ and GBF report no conflicts of interest.

Open Access This article is licensed under a Creative Commons Attribution 4.0 International License, which permits use, sharing, adaptation, distribution and reproduction in any medium or format, as long as you give appropriate credit to the original author(s) and the source, provide a link to the Creative Commons licence, and indicate if changes were made. The images or other third party material in this article are included in the article's Creative Commons licence, unless indicated otherwise in a credit line to the material. If material is not included in the article's Creative Commons licence and your intended use is not permitted by statutory regulation or exceeds the permitted use, you will need to obtain permission directly from the copyright holder. To view a copy of this licence, visit http://creativecommons.org/licenses/by/4.0/.

\section{References}

1. Pepe MS, Etzioni R, Feng Z, Potter JD, Thompson ML, Thornquist M, et al. Phases of biomarker development for early detection of cancer. J Natl Cancer Inst. 2001;93(14):1054-61.

2. Boccardi M, Gallo V, Yasui Y, Vineis P, Padovani A, Mosimann $\mathrm{U}$, et al. The biomarker-based diagnosis of Alzheimer's disease. 2lessons from oncology. Neurobiol Aging. 2017;52:141-52.

3. Frisoni GB, Perani D, Bastianello S, Bernardi G, Porteri C, Boccardi M, et al. Biomarkers for the diagnosis of Alzheimer's disease in clinical practice: an Italian intersocietal roadmap. Neurobiol Aging. 2017;52:119-31.

4. Cerami C, Dubois B, Boccardi M, Monsch AU, Demonet JF, Cappa SF, et al. Clinical validity of delayed recall tests as a gateway biomarker for Alzheimer's disease in the context of a structured 5-phase development framework. Neurobiol Aging. 2017;52:153-66.

5. Ten Kate M, Barkhof F, Boccardi M, Visser PJ, Jack CR Jr, Lovblad KO, et al. Clinical validity of medial temporal atrophy as a biomarker for Alzheimer's disease in the context of a structured 5-phase development framework. Neurobiol Aging. 2017;52:167-82 e1.

6. Garibotto V, Herholz K, Boccardi M, Picco A, Varrone A, Nordberg A, et al. Clinical validity of brain fluorodeoxyglucose positron emission tomography as a biomarker for Alzheimer's disease in the context of a structured 5-phase development framework. Neurobiol Aging. 2017;52:183-95.

7. Chiotis K, Saint-Aubert L, Boccardi M, Gietl A, Picco A, Varrone A, et al. Clinical validity of increased cortical uptake of amyloid ligands on PET as a biomarker for Alzheimer's disease in the context of a structured 5-phase development framework. Neurobiol Aging. 2017;52:214-27.

8. Sonni I, Ratib O, Boccardi M, Picco A, Herholz K, Nobili F, et al. Clinical validity of presynaptic dopaminergic imaging with (123)I-ioflupane and noradrenergic imaging with (123)I-MIBG in the differential diagnosis between Alzheimer's disease and dementia with Lewy bodies in the context of a structured 5-phase development framework. Neurobiol Aging. 2017;52:228-42.

9. Mattsson N, Lonneborg A, Boccardi M, Blennow K, Hansson O, B. Geneva Task Force for the Roadmap of Alzheimer's. Clinical validity of cerebrospinal fluid Abeta42, tau, and phospho-tau as biomarkers for Alzheimer's disease in the context of a structured 5phase development framework. Neurobiol Aging. 2017;52:196213.

10. Leuzy A, Ashton NJ, Mattsson-Carlgren N, Dodich A, Boccardi M, Corre11 J, et al. 2020 update on the clinical validity of cerebrospinal fluid amyloid, tau, and phospho-tau as biomarkers for Alzheimer's disease in the context of a structured 5-phase development framework. 2021. https://doi.org/10.1007/s00259-02105258-7.

11. Olsson B, Lautner R, Andreasson U, Ohrfelt A, Portelius E, Bjerke M, et al. CSF and blood biomarkers for the diagnosis of Alzheimer's disease: a systematic review and meta-analysis. Lancet Neurol. 2016;15(7):673-84.

12. Hye A, Lynham S, Thambisetty M, Causevic M, Campbell J, Byers HL, et al. Proteome-based plasma biomarkers for Alzheimer's disease. Brain. 2006;129(Pt 11):3042-50.

13. Shi L, Baird AL, Westwood S, Hye A, Dobson R, Thambisetty M, et al. A decade of blood biomarkers for Alzheimer's disease research: an evolving field, improving study designs, and the challenge of replication. J Alzheimers Dis. 2018;62(3):1181-98.

14. Ray S, Britschgi M, Herbert C, Takeda-Uchimura Y, Boxer A, Blennow K, et al. Classification and prediction of clinical Alzheimer's diagnosis based on plasma signaling proteins. Nat Med. 2007;13(11):1359-62.

15. Mapstone M, Cheema AK, Fiandaca MS, Zhong X, Mhyre TR, MacArthur LH, et al. Plasma phospholipids identify antecedent memory impairment in older adults. Nat Med. 2014;20(4):415-8.

16. Westwood S, Baird AL, Hye A, Ashton NJ, Nevado-Holgado AJ, Anand SN, et al. Plasma protein biomarkers for the prediction of CSF amyloid and tau and [(18)F]-flutemetamol PET scan result. Front Aging Neurosci. 2018;10:409.

17. Westwood S, Baird AL, Anand SN, Nevado-Holgado AJ, Kormilitzin A, Shi L, et al. Validation of plasma proteomic biomarkers relating to brain amyloid burden in the EMIFAlzheimer's disease multimodal biomarker discovery cohort. J Alzheimers Dis. 2020;74(1):213-25.

18. Ashton NJ, Nevado-Holgado AJ, Barber IS, Lynham S, Gupta V, Chatterjee $\mathrm{P}$, et al. A plasma protein classifier for predicting amyloid burden for preclinical Alzheimer's disease. Sci Adv. 2019;5(2):eaau7220.

19. Blennow K, Zetterberg H. Biomarkers for Alzheimer's disease: current status and prospects for the future. J Intern Med. 2018;284(6):643-63.

20. Ashton NJ, Hye A, Rajkumar AP, Leuzy A, Snowden S, SuarezCalvet M, et al. An update on blood-based biomarkers for nonAlzheimer neurodegenerative disorders. Nat Rev Neurol. 2020;16(5):265-84.

21. Mattsson N, Andreasson U, Zetterberg H, Blennow K, I. Alzheimer's Disease Neuroimaging. Association of Plasma Neurofilament Light With Neurodegeneration in Patients With Alzheimer Disease. JAMA Neurol. 2017;74(5):557-66.

22. Mattsson N, Cullen NC, Andreasson U, Zetterberg H, Blennow K. Association between longitudinal plasma neurofilament light and neurodegeneration in patients with Alzheimer disease. JAMA Neurol. 2019;76(7):791-9.

23. Ashton NJ, Leuzy A, Lim YM, Troakes C, Hortobagyi T, Hoglund $\mathrm{K}$, et al. Increased plasma neurofilament light chain concentration correlates with severity of post-mortem neurofibrillary tangle pathology and neurodegeneration. Acta Neuropathol Commun. 2019;7(1):5.

24. Benedet AL, Ashton NJ, Pascoal TA, Leuzy A, Mathotaarachchi $\mathrm{S}$, Kang MS, et al. Plasma neurofilament light associates with Alzheimer's disease metabolic decline in amyloid-positive individuals. Alzheimers Dement (Amst). 2019;11:679-89. 
25. Simrén J, Leuzy A, Karikari TK, Hye A, Benedet AL, LanteroRodriguez J, et al. The diagnostic and prognostic capabilities of plasma biomarkers in Alzheimer's disease. Alzheimers Dement. 2021. https://doi.org/10.1002/alz.12283.

26. Hansson O, Janelidze S, Hall S, Magdalinou N, Lees AJ, Andreasson U, et al. Blood-based NfL: a biomarker for differential diagnosis of parkinsonian disorder. Neurology. 2017;88(10): 930-7.

27. Ashton NJ, Janelidze S, Al-Khleifat A, Leuzy A, Van der Ende EL, Karikari TK, et al. Diagnostic value of plasma neurofilament light: a multicentre validation study. Research Square. 2020. https://doi.org/ 10.21203/rs.3.rs-63386/v1 (PREPRINT (Version 1)).

28. Wihersaari L, Ashton NJ, Reinikainen M, Jakkula P, Pettila V, Hastbacka J, et al. Neurofilament light as an outcome predictor after cardiac arrest: a post hoc analysis of the COMACARE trial. Intensive Care Med. 2020. https://doi.org/10.1007/s00134-02006218-9.

29. Mattsson N, Zetterberg H, Janelidze S, Insel PS, Andreasson U, Stomrud E, et al. Plasma tau in Alzheimer disease. Neurology. 2016;87(17):1827-35.

30. Zetterberg H, Wilson D, Andreasson U, Minthon L, Blennow K, Randall J, et al. Plasma tau levels in Alzheimer's disease. Alzheimers Res Ther. 2013;5(2):9.

31. Chen Z, Mengel D, Keshavan A, Rissman RA, Billinton A, Perkinton $\mathrm{M}$, et al. Learnings about the complexity of extracellular tau aid development of a blood-based screen for Alzheimer's disease. Alzheimers Dement. 2019;15(3):487-96.

32. Mengel D, Janelidze S, Glynn RJ, Liu W, Hansson O, Walsh DM. Plasma NT1 tau is a specific and early marker of Alzheimer's disease. Ann Neurol. 2020;88(5):878-92.

33. Boccardi M, Dodich A, Albanese E, Gayet-Ageron A, Festari C, Ramusino M, et al. The strategic biomarker roadmap for the validation of Alzheimer's diagnostic biomarkers: methodological update. EJNMMI. 2021. https://doi.org/10.1007/s00259-020-051202.

34. Jack CR Jr, Bennett DA, Blennow K, Carrillo MC, Dunn B, Haeberlein SB, et al. NIA-AA Research Framework: Toward a biological definition of Alzheimer's disease. Alzheimers Dement. 2018;14(4):535-62.

35. McKhann G, Drachman D, Folstein M, Katzman R, Price D, Stadlan EM. Clinical diagnosis of Alzheimer's disease: report of the NINCDS-ADRDA work group under the auspices of Department of Health and Human Services Task Force on Alzheimer's disease. Neurology. 1984;34(7):939-44.

36. Beach TG, Monsell SE, Phillips LE, Kukull W. Accuracy of the clinical diagnosis of Alzheimer disease at National Institute on Aging Alzheimer Disease Centers, 2005-2010. J Neuropathol Exp Neurol. 2012;71(4):266-73.

37. Bennett DA, Wilson RS, Schneider JA, Evans DA, Beckett LA, Aggarwal NT, et al. Natural history of mild cognitive impairment in older persons. Neurology. 2002;59(2):198-205.

38. Jack CR Jr, Lowe VJ, Senjem ML, Weigand SD, Kemp BJ, Shiung MM, et al. 11C PiB and structural MRI provide complementary information in imaging of Alzheimer's disease and amnestic mild cognitive impairment. Brain. 2008;131(Pt 3):66580.

39. Dubois B, Feldman HH, Jacova C, Hampel H, Molinuevo JL, Blennow $\mathrm{K}$, et al. Advancing research diagnostic criteria for Alzheimer's disease: the IWG-2 criteria. Lancet Neurol. 2014;13(6):614-29.

40. Albert MS, DeKosky ST, Dickson D, Dubois B, Feldman HH, Fox NC, et al. The diagnosis of mild cognitive impairment due to Alzheimer's disease: recommendations from the National Institute on Aging-Alzheimer's Association workgroups on diagnostic guidelines for Alzheimer's disease. Alzheimers Dement. 2011;7(3):270-9.
41. Masters CL, Simms G, Weinman NA, Multhaup G, McDonald BL, Beyreuther K. Amyloid plaque core protein in Alzheimer disease and Down syndrome. Proc Natl Acad Sci U S A. 1985;82(12):4245-9.

42. Jarrett JT, Berger EP, Lansbury PT Jr. The carboxy terminus of the beta amyloid protein is critical for the seeding of amyloid formation: implications for the pathogenesis of Alzheimer's disease. Biochemistry. 1993;32(18):4693-7.

43. Grundke-Iqbal I, Iqbal K, Quinlan M, Tung YC, Zaidi MS, Wisniewski HM. Microtubule-associated protein tau. A component of Alzheimer paired helical filaments. J Biol Chem. 1986;261(13):6084-9.

44. Grundke-Iqbal I, Iqbal K, Tung YC, Quinlan M, Wisniewski HM, Binder LI. Abnormal phosphorylation of the microtubuleassociated protein tau (tau) in Alzheimer cytoskeletal pathology. Proc Natl Acad Sci U S A. 1986;83(13):4913-7.

45. Seubert P, Vigo-Pelfrey C, Esch F, Lee M, Dovey H, Davis D, et al. Isolation and quantification of soluble Alzheimer's betapeptide from biological fluids. Nature. 1992;359(6393):325-7.

46. Motter R, Vigo-Pelfrey C, Kholodenko D, Barbour R, JohnsonWood K, Galasko D, et al. Reduction of beta-amyloid peptide42 in the cerebrospinal fluid of patients with Alzheimer's disease. Ann Neurol. 1995;38(4):643-8.

47. Shoji M, Matsubara E, Kanai M, Watanabe M, Nakamura T, Tomidokoro Y, et al. Combination assay of CSF tau, a beta 1-40 and a beta 1-42(43) as a biochemical marker of Alzheimer's disease. J Neurol Sci. 1998;158(2):134-40.

48. Blennow K, Wallin A, Agren H, Spenger C, Siegfried J, Vanmechelen E. Tau protein in cerebrospinal fluid: a biochemical marker for axonal degeneration in Alzheimer disease? Mol Chem Neuropathol. 1995;26(3):231-45.

49. Iqbal K, Grundke-Iqbal I. Elevated levels of tau and ubiquitin in brain and cerebrospinal fluid in Alzheimer's disease. Int Psychogeriatr. 1997;9(Suppl 1):289-96 discussion 317-21.

50. Ashton NJ, Scholl M, Heurling K, Gkanatsiou E, Portelius E, Hoglund K, et al. Update on biomarkers for amyloid pathology in Alzheimer's disease. Biomark Med. 2018;12(7):799-812.

51. Janelidze S, Pannee J, Mikulskis A, Chiao P, Zetterberg H, Blennow K, et al. Concordance between different amyloid immunoassays and visual amyloid positron emission tomographic assessment. JAMA Neurol. 2017;74(12):1492-501.

52. La Joie R, Bejanin A, Fagan AM, Ayakta N, Baker SL, Bourakova V, et al. Associations between [(18)F]AV1451 tau PET and CSF measures of tau pathology in a clinical sample. Neurology. 2018;90(4):e282-90.

53. Mattsson N, Scholl M, Strandberg O, Smith R, Palmqvist S, Insel PS, et al. (18)F-AV-1451 and CSF T-tau and P-tau as biomarkers in Alzheimer's disease. EMBO Mol Med. 2017;9(9):1212-23.

54. Bateman RJ, Xiong C, Benzinger TL, Fagan AM, Goate A, Fox $\mathrm{NC}$, et al. Clinical and biomarker changes in dominantly inherited Alzheimer's disease. N Engl J Med. 2012;367(9):795-804.

55. Barthelemy NR, Li Y, Joseph-Mathurin N, Gordon BA, Hassenstab J, Benzinger TLS, et al. A soluble phosphorylated tau signature links tau, amyloid and the evolution of stages of dominantly inherited Alzheimer's disease. Nat Med. 2020;26(3): 398-407.

56. Mattsson-Carlgren N, Andersson E, Janelidze S, Ossenkoppele R, Insel $\mathrm{P}$, Strandberg $\mathrm{O}$, et al. Abeta deposition is associated with increases in soluble and phosphorylated tau that precede a positive tau PET in Alzheimer's disease. Sci Adv. 2020;6(16):eaaz2387.

57. Toledo JB, Xie SX, Trojanowski JQ, Shaw LM. Longitudinal change in CSF tau and Abeta biomarkers for up to 48 months in ADNI. Acta Neuropathol. 2013;126(5):659-70.

58. Suarez-Calvet M, Karikari TK, Ashton NJ, Rodriguez JL, MilaAloma M, Gispert JD, et al. Novel tau biomarkers phosphorylated at T181, T217 or T231 rise in the initial stages of the preclinical 
Alzheimer's continuum when only subtle changes in Abeta pathology are detected. EMBO Mol Med. 2020;12(12):e12921. https://doi.org/10.15252/emmm.202012921.

59. Sato C, Barthelemy NR, Mawuenyega KG, Patterson BW, Gordon BA, Jockel-Balsarotti J, et al. Tau kinetics in neurons and the human central nervous system. Neuron. 2018;97(6): 1284-1298 e7.

60. Song F, Poljak A, Valenzuela M, Mayeux R, Smythe GA, Sachdev PS. Meta-analysis of plasma amyloid-beta levels in Alzheimer's disease. J Alzheimers Dis. 2011;26(2):365-75.

61. Hansson O, Zetterberg H, Vanmechelen E, Vanderstichele H, Andreasson U, Londos E, et al. Evaluation of plasma Abeta(40) and Abeta(42) as predictors of conversion to Alzheimer's disease in patients with mild cognitive impairment. Neurobiol Aging. 2010;31(3):357-67.

62. Kuo YM, Emmerling MR, Lampert HC, Hempelman SR, Kokjohn TA, Woods AS, et al. High levels of circulating Abeta42 are sequestered by plasma proteins in Alzheimer's disease. Biochem Biophys Res Commun. 1999;257(3):787-91.

63. Zetterberg H, Mortberg E, Song L, Chang L, Provuncher GK, Patel PP, et al. Hypoxia due to cardiac arrest induces a timedependent increase in serum amyloid beta levels in humans. PLoS One. 2011;6(12):e28263.

64. Janelidze S, Stomrud E, Palmqvist S, Zetterberg H, van Westen D, Jeromin A, et al. Plasma beta-amyloid in Alzheimer's disease and vascular disease. Sci Rep. 2016;6:26801.

65. Pannee J, Tornqvist U, Westerlund A, Ingelsson M, Lannfelt L, Brinkmalm G, et al. The amyloid-beta degradation pattern in plasma-a possible tool for clinical trials in Alzheimer's disease. Neurosci Lett. 2014;573:7-12.

66. Ovod V, Ramsey KN, Mawuenyega KG, Bollinger JG, Hicks T, Schneider T, et al. Amyloid beta concentrations and stable isotope labeling kinetics of human plasma specific to central nervous system amyloidosis. Alzheimers Dement. 2017;13(8):841-9.

67. Kaneko N, Nakamura A, Washimi Y, Kato T, Sakurai T, Arahata Y, et al. Novel plasma biomarker surrogating cerebral amyloid deposition. Proc Jpn Acad Ser B Phys Biol Sci. 2014;90(9):35364.

68. Tzen KY, Yang SY, Chen TF, Cheng TW, Horng HE, Wen HP, et al. Plasma Abeta but not tau is related to brain PiB retention in early Alzheimer's disease. ACS Chem Neurosci. 2014;5(9):830 6.

69. Randall J, Mortberg E, Provuncher GK, Fournier DR, Duffy DC, Rubertsson S, et al. Tau proteins in serum predict neurological outcome after hypoxic brain injury from cardiac arrest: results of a pilot study. Resuscitation. 2013;84(3):351-6.

70. Shahim P, Tegner Y, Wilson DH, Randall J, Skillback T, Pazooki $\mathrm{D}$, et al. Blood biomarkers for brain injury in concussed professional ice hockey players. JAMA Neurol. 2014;71(6):684-92.

71. Evered L, Silbert B, Scott DA, Zetterberg H, Blennow K. Association of changes in plasma neurofilament light and tau levels with anesthesia and surgery: results from the CAPACITY and ARCADIAN studies. JAMA Neurol. 2018;75(5):542-7.

72. Pereira JB, Westman E, Hansson O, I. Alzheimer's Disease Neuroimaging. Association between cerebrospinal fluid and plasma neurodegeneration biomarkers with brain atrophy in Alzheimer's disease. Neurobiol Aging. 2017;58:14-29.

73. Ashton NJ, Ide M, Zetterberg H, Blennow K. Salivary biomarkers for Alzheimer's disease and related disorders. Neurol Ther. 2019;8(Suppl 2):83-94.

74. Ashton NJ, Ide M, Scholl M, Blennow K, Lovestone S, Hye A, et al. No association of salivary total tau concentration with Alzheimer's disease. Neurobiol Aging. 2018;70:125-7.

75. Suarez-Calvet M, Karikari TK, Ashton NJ, Lantero-Rodriguez J, Mila-Aloma M, Gispert JD, et al. Novel tau biomarkers phosphorylated at T181, T217 or T231 rise in the initial stages of the preclinical Alzheimer's continuum when only subtle changes in $\mathrm{Ab}$ pathology are detected. EMBO Mol Med. 2020. https://doi. org/10.15252/emmm.202012921.

76. Tatebe H, Kasai T, Ohmichi T, Kishi Y, Kakeya T, Waragai M, et al. Quantification of plasma phosphorylated tau to use as a biomarker for brain Alzheimer pathology: pilot case-control studies including patients with Alzheimer's disease and down syndrome. Mol Neurodegener. 2017;12(1):63.

77. Mielke MM, Hagen CE, Xu J, Chai X, Vemuri P, Lowe VJ, et al. Plasma phospho-tau181 increases with Alzheimer's disease clinical severity and is associated with tau- and amyloid-positron emission tomography. Alzheimers Dement. 2018;14(8):989-97.

78. Palmqvist S, Insel PS, Stomrud E, Janelidze S, Zetterberg H, Brix $\mathrm{B}$, et al. Cerebrospinal fluid and plasma biomarker trajectories with increasing amyloid deposition in Alzheimer's disease. EMBO Mol Med. 2019;11(12):e11170.

79. Karikari TK, Pascoal TA, Ashton NJ, Janelidze S, Benedet AL, Rodriguez JL, et al. Blood phosphorylated tau 181 as a biomarker for Alzheimer's disease: a diagnostic performance and prediction modelling study using data from four prospective cohorts. Lancet Neurol. 2020;19(5):422-33.

80. Janelidze S, Mattsson N, Palmqvist S, Smith R, Beach TG, Serrano GE, et al. Plasma P-tau181 in Alzheimer's disease: relationship to other biomarkers, differential diagnosis, neuropathology and longitudinal progression to Alzheimer's dementia. Nat Med. 2020;26(3):379-86.

81. Thijssen EH, La Joie R, Wolf A, Strom A, Wang P, Iaccarino L, et al. Treatment for frontotemporal lobar degeneration, diagnostic value of plasma phosphorylated tau181 in Alzheimer's disease and frontotemporal lobar degeneration. Nat Med. 2020;26(3):387-97.

82. Palmqvist S, Janelidze S, Quiroz YT, Zetterberg H, Lopera F, Stomrud E, et al. Discriminative accuracy of plasma phosphotau217 for Alzheimer disease vs other neurodegenerative disorders. JAMA. 2020;324(8):772-81.

83. Ashton NJ, Pascoal TA, Karikari TK, Benedet AL, LanteroRodriguez J, Brinkmalm G, et al. Plasma p-tau231: a new biomarker for incipient Alzheimer's disease pathology. Acta Neuropathol. 2021. https://doi.org/10.1007/s00401-021-02275-6.

84. Startin CM, Ashton NJ, Hamburg S, Hithersay R, Wiseman FK, Mok KY, et al. Plasma biomarkers for amyloid, tau, and cytokines in down syndrome and sporadic Alzheimer's disease. Alzheimers Res Ther. 2019;11(1):26.

85. Palmqvist S, Janelidze S, Stomrud E, Zetterberg H, Karl J, Zink K, et al. Performance of fully automated plasma assays as screening tests for Alzheimer disease-related $\beta$-amyloid status. JAMA Neurol. 2019;76(9):1060-9. https://doi.org/10.1001/jamaneurol. 2019.1632 .

86. Schindler SE, Bollinger JG, Ovod V, Mawuenyega KG, Li Y, Gordon BA, et al. High-precision plasma beta-amyloid $42 / 40$ predicts current and future brain amyloidosis. Neurology. 2019;93(17):e1647-59.

87. Nakamura A, Kaneko N, Villemagne VL, Kato T, Doecke J, Dore $\mathrm{V}$, et al. High performance plasma amyloid-beta biomarkers for Alzheimer's disease. Nature. 2018;554(7691):249-54.

88. Chiu MJ, Chen TF, Hu CJ, Yan SH, Sun Y, Liu BH, et al. Nanoparticle-based immunomagnetic assay of plasma biomarkers for differentiating dementia and prodromal states of Alzheimer's disease - a cross-validation study. Nanomedicine. 2020;28: 102182.

89. Lin CH, Yang SY, Horng HE, Yang CC, Chieh JJ, Chen HH, et al. Plasma biomarkers differentiate Parkinson's disease from atypical parkinsonism syndromes. Front Aging Neurosci. 2018;10:123.

90. Rabinovici GD, Furst AJ, O'Neil JP, Racine CA, Mormino EC, Baker SL, et al. 11C-PIB PET imaging in Alzheimer disease and frontotemporal lobar degeneration. Neurology. 2007;68(15): 1205-12. 
91. Struyfs H, Niemantsverdriet E, Goossens J, Fransen E, Martin JJ, De Deyn PP, et al. Cerebrospinal fluid P-Tau181P: biomarker for improved differential dementia diagnosis. Front Neurol. 2015;6:138.

92. Janelidze S, Stomrud E, Smith R, Palmqvist S, Mattsson N, Airey DC, et al. Cerebrospinal fluid p-tau 217 performs better than $\mathrm{p}$ tau181 as a biomarker of Alzheimer's disease. Nat Commun. 2020;11(1):1683.

93. Karikari TK, Emersic A, Vrillon A, Lantero-Rodriguez J, Ashton NJ, Kramberger MG, et al. Head-to-head comparison of clinical performance of CSF phospho-tau T181 and T217 biomarkers for Alzheimer's disease diagnosis. Alzheimers Dement. 2020. https:// doi.org/10.1002/alz.12236.

94. Barthelemy NR, Bateman RJ, Hirtz C, Marin P, Becher F, Sato C, et al. Cerebrospinal fluid phospho-tau T217 outperforms T181 as a biomarker for the differential diagnosis of Alzheimer's disease and PET amyloid-positive patient identification. Alzheimers Res Ther. 2020;12(1):26.

95. Hanes J, Kovac A, Kvartsberg H, Kontsekova E, Fialova L, Katina S, et al. Evaluation of a novel immunoassay to detect $\mathrm{p}$ tau Thr217 in the CSF to distinguish Alzheimer disease from other dementias. Neurology. 2020. https://doi.org/10.1212/WNL. 0000000000010814 .

96. Ashton NJ, Benedet AL, Pascoal TA, Karikari TK, LanteroRodriguez J, Mathotaarachchi S, et al. Cerebrospinal fluid ptau231 as an early indicator of emerging pathology in Alzheimer's disease. Research Square 2021. https://doi.org/10. 21203/rs.3.rs-155736/v1 (PREPRINT (Version 1)).

97. Benussi A, Karikari TK, Ashton N, Gazzina S, Premi E, Benussi $\mathrm{L}$, et al. Diagnostic and prognostic value of serum NfL and pTau181 in frontotemporal lobar degeneration. J Neurol Neurosurg Psychiatry. 2020;91(9):960-7.

98. Lantero Rodriguez J, Karikari TK, Suarez-Calvet M, Troakes C, King A, Emersic A, et al. Plasma p-tau181 accurately predicts Alzheimer's disease pathology at least 8 years prior to postmortem and improves the clinical characterisation of cognitive decline. Acta Neuropathol. 2020;140(3):267-78.

99. Barthélemy NR, Horie K, Sato C, Bateman RJ. Blood plasma phosphorylated-tau isoforms track CNS change in Alzheimer's disease. J Exp Med. 2020;217(11):e20200861. https://doi.org/10. 1084/jem.20200861.

100. O'Bryant SE, Gupta V, Henriksen K, Edwards M, Jeromin A, Lista $\mathrm{S}$, et al. Guidelines for the standardization of preanalytic variables for blood-based biomarker studies in Alzheimer's disease research. Alzheimers Dement. 2015;11(5):549-60.

101. Rozga M, Bittner T, Batrla R, Karl J. Preanalytical sample handling recommendations for Alzheimer's disease plasma biomarkers. Alzheimers Dement (Amst). 2019;11:291-300.

102. Verberk IMW, Thijssen E, Koelewijn J, Mauroo K, Vanbrabant J, de Wilde A, et al. Combination of plasma amyloid beta(1-42/1-40) and glial fibrillary acidic protein strongly associates with cerebral amyloid pathology. Alzheimers Res Ther. 2020;12(1):118.

103. Verberk IMW, Slot RE, Verfaillie SCJ, Heijst H, Prins ND, van Berckel BNM, et al. Plasma amyloid as prescreener for the earliest Alzheimer pathological changes. Ann Neurol. 2018;84(5):648-58.

104. Vogelgsang J, Vukovich R, Wedekind D, Wiltfang J. Higher level of mismatch in APOEepsilon4 carriers for amyloid-beta peptide Alzheimer's disease biomarkers in cerebrospinal fluid. ASN Neuro. 2019;11:1759091419845524.

105. Lim CZJ, Zhang Y, Chen Y, Zhao H, Stephenson MC, Ho NRY, et al. Subtyping of circulating exosome-bound amyloid beta reflects brain plaque deposition. Nat Commun. 2019;10(1):1144.

106. Mattsson-Carlgren N, Janelidze S, Palmqvist S, Cullen N, Svenningsson AL, Strandberg O, et al. Longitudinal plasma ptau217 is increased in early stages of Alzheimer's disease. Brain. 2020;143(11):3234-41. https://doi.org/10.1093/brain/ awaa286.
107. Benussi A, Ashton NJ, Karikari TK, Gazzina S, Premi E, Benussi $\mathrm{L}$, et al. Serum glial fibrillary acidic protein (GFAP) is a marker of disease severity in frontotemporal lobar degeneration. J Alzheimers Dis. 2020;77(3):1129-41.

108. Gamache J, Yun Y, Chiba-Falek O. Sex-dependent effect of APOE on Alzheimer's disease and other age-related neurodegenerative disorders. Dis Model Mech. 2020;13(8):dmm045211. https://doi.org/10.1242/dmm.045211.

109. Babapour Mofrad R, Tijms BM, Scheltens P, Barkhof F, van der Flier WM, Sikkes SAM, et al. Sex differences in CSF biomarkers vary by Alzheimer's disease stage and APOE $\varepsilon 4$ genotype. Neurology. 2020;27;95(17):e2378-88. https://doi.org/10.1212/ WNL.0000000000010629.

110. Nakamura T, Kawarabayashi T, Seino Y, Hirohata M, Nakahata $\mathrm{N}$, Narita S, et al. Aging and APOE-epsilon4 are determinative factors of plasma Abeta42 levels. Ann Clin Transl Neurol. 2018;5(10):1184-91.

111. Knapskog AB, Eldholm RS, Braekhus A, Engedal K, Saltvedt I. Factors that influence the levels of cerebrospinal fluid biomarkers in memory clinic patients. BMC Geriatr. 2017;17(1):210.

112. Cullen NC, Leuzy A, Palmqvist S, Janelidze S, Stomrud E, Pesini $\mathrm{P}$, et al. Individualized prognosis of cognitive decline and dementia in mild cognitive impairment based on plasma biomarker combinations. Nat Aging. 2021;1:114-23. https://doi.org/10.1038/ s43587-020-00003-5.

113. Karikari TK, Benedet AL, Ashton NJ, Lantero-Rodriguez J, Snellman A, Suarez-Calvet M, et al. Diagnostic performance and prediction of clinical progression of plasma phospho-tau181 in the Alzheimer's Disease Neuroimaging Initiative. Mol Psychiatry. 2020. https://doi.org/10.1038/s41380-020-00923-z.

114. O'Connor A, Karikari TK, Poole T, Ashton NJ, LanteroRodriguez J, Khatun A, et al. Plasma phospho-tau181 in presymptomatic and symptomatic familial Alzheimer's disease: a longitudinal cohort study. Mol Psychiatry. 2020. https://doi.org/10.1038/ s41380-020-0838-x.

115. Pase MP, Beiser AS, Himali JJ, Satizabal CL, Aparicio HJ, DeCarli C, et al. Assessment of plasma Total tau level as a predictive biomarker for dementia and related endophenotypes. JAMA Neurol. 2019;76(5):598-606.

116. Kanberg N, Ashton NJ, Andersson LM, Yilmaz A, Lindh M, Nilsson S, et al. Neurochemical evidence of astrocytic and neuronal injury commonly found in COVID-19. Neurology. 2020;95(12):e1754-9.

117. Hanes J, Kovac A, Kvartsberg H, Kontsekova E, Fialova L, Katina S, et al. Evaluation of a novel immunoassay to detect $\mathrm{p}$ tau Thr127 in the CSF to distinguish Alzheimer disease from other dementias. Neurology. 2020.

118. Janelidze S, Stomrud E, Brix B, Hansson O. Towards a unified protocol for handling of CSF before $\beta$-amyloid measurements. Alzheimers Res Ther. 2019;11(1):63. https://doi.org/10.1186/ s13195-019-0517-9.

119. Rajan KB, Aggarwal NT, McAninch EA, Weuve J, Barnes LL, Wilson RS, et al. Remote blood biomarkers of longitudinal cognitive outcomes in a population study. Ann Neurol. 2020.

120. Vanderstichele H, De Vreese K, Blennow K, Andreasen N, Sindic C, Ivanoiu A, et al. Analytical performance and clinical utility of the INNOTEST PHOSPHO-TAU181P assay for discrimination between Alzheimer's disease and dementia with Lewy bodies. Clin Chem Lab Med. 2006;44(12):1472-80. https://doi.org/10. 1515/CCLM.2006.258.

121. Leitao MJ, Silva-Spinola A, Santana I, Olmedo V, Nadal A, Le Bastard N, et al. Clinical validation of the lumipulse G cerebrospinal fluid assays for routine diagnosis of Alzheimer's disease. Alzheimers Res Ther. 2019;11(1):91.

122. Lifke V, Kollmorgen G, Manuilova E, Oelschlaegel T, Hillringhaus L, Widmann M, et al. Elecsys((R)) total-tau and 
phospho-tau (181P) CSF assays: analytical performance of the novel, fully automated immunoassays for quantification of tau proteins in human cerebrospinal fluid. Clin Biochem. 2019;72: $30-8$.

123. Cicognola C, Brinkmalm G, Wahlgren J, Portelius E, Gobom J, Cullen NC, et al. Novel tau fragments in cerebrospinal fluid: relation to tangle pathology and cognitive decline in Alzheimer's disease. Acta Neuropathol. 2019;137(2):279-96.

124. Basurto-Islas G, Luna-Munoz J, Guillozet-Bongaarts AL, Binder LI, Mena R, Garcia-Sierra F. Accumulation of aspartic acid421and glutamic acid391-cleaved tau in neurofibrillary tangles correlates with progression in Alzheimer disease. J Neuropathol Exp Neurol. 2008;67(5):470-83.

125. Fitzpatrick AWP, Falcon B, He S, Murzin AG, Murshudov G, Garringer HJ, et al. Cryo-EM structures of tau filaments from Alzheimer's disease. Nature. 2017;547(7662):185-90.

126. Yang CC, Chiu MJ, Chen TF, Chang HL, Liu BH, Yang SY. Assay of plasma phosphorylated tau protein (threonine 181) and total tau protein in early-stage Alzheimer's disease. J Alzheimers Dis. 2018;61(4):1323-32.

127. O'Brien RJ, Wong PC. Amyloid precursor protein processing and Alzheimer's disease. Annu Rev Neurosci. 2011;34:185-204.

128. Citron M, Vigo-Pelfrey C, Teplow DB, Miller C, Schenk D, Johnston J, et al. Excessive production of amyloid beta-protein by peripheral cells of symptomatic and presymptomatic patients carrying the Swedish familial Alzheimer disease mutation. Proc Natl Acad Sci U S A. 1994;91(25):11993-7.

129. Bielinska K, Radkowski M, Grochowska M, Perlejewski K, Huc $\mathrm{T}$, Jaworska K, et al. High salt intake increases plasma trimethylamine $\mathrm{N}$-oxide (TMAO) concentration and produces gut dysbiosis in rats. Nutrition. 2018;54:33-9.

130. Komi R, Tanaka F, Omama S, Ishibashi Y, Tanno K, Onoda T, et al. Burden of high blood pressure as a contributing factor to stroke in the Japanese community-based diabetic population. Hypertens Res. 2018;41(7):531-8.

131. Strozyk D, Blennow K, White LR, Launer LJ. CSF Abeta 42 levels correlate with amyloid-neuropathology in a populationbased autopsy study. Neurology. 2003;60(4):652-6.

132. Ikonomovic MD, Klunk WE, Abrahamson EE, Mathis CA, Price JC, Tsopelas ND, et al. Post-mortem correlates of in vivo PiB-PET amyloid imaging in a typical case of Alzheimer's disease. Brain. 2008;131(Pt 6):1630-45.

133. Clark CM, Schneider JA, Bedell BJ, Beach TG, Bilker WB, Mintun MA, et al. Use of florbetapir-PET for imaging betaamyloid pathology. JAMA. 2011;305(3):275-83.

Publisher's note Springer Nature remains neutral with regard to jurisdictional claims in published maps and institutional affiliations.

\section{Affiliations}

\section{N. J. Ashton ${ }^{1,2,3}$ (D) A. Leuzy ${ }^{4}$ - T. K. Karikari ${ }^{1}$ • N. Mattsson-Carlgren ${ }^{4,5,6} \cdot$ A. Dodich $^{7,8}$ - M. Boccardi ${ }^{9,10}$ - J. Corre ${ }^{11}$. A. Drzezga ${ }^{12} \cdot$ A. Nordberg ${ }^{13,14} \cdot$ R. Ossenkoppele ${ }^{4,15} \cdot$ H. Zetterberg ${ }^{1,16,17,18} \cdot$ K. Blennow $^{1,16} \cdot$ G. B. Frisoni ${ }^{9,19}$. V. Garibotto ${ }^{7,20} \cdot$ O. Hansson ${ }^{4,18,21}$}

1 Institute of Neuroscience \& Physiology, Department of Psychiatry \& Neurochemistry, Sahlgrenska Academy, University of Gothenburg, House V3/SU, SE-431 80 Mölndal, Sweden

2 Department of Old Age Psychiatry, Institute of Psychiatry, Psychology \& Neuroscience, King's College London, London, UK

3 Wallenberg Centre for Molecular and Translational Medicine, University of Gothenburg, Gothenburg, Sweden

4 Clinical Memory Research Unit, Department of Clinical Sciences, Malmö, Lund University, Lund, Sweden

5 Department of Neurology, Skåne University Hospital, Lund, Sweden

6 Wallenberg Centre for Molecular Medicine, Lund University, Lund, Sweden

$7 \quad$ NIMTlab - Neuroimaging and Innovative Molecular Tracers Laboratory, University of Geneva, Geneva, Switzerland

8 Center for Neurocognitive Rehabilitation (CeRiN), CIMeC, University of Trento, Trento, Italy

9 German Center for Neurodegenerative Diseases (DZNE), RostockGreifswald, Rostock, Germany

10 LANVIE - Laboratory of Neuroimaging of Aging, University of Geneva, Geneva, Switzerland
11 Centre National de la Recherche Scientifique, Montpellier, France

12 Medical Faculty and University Hospital of Cologne, Cologne, Germany

13 Division of Clinical Geriatrics, Center for Alzheimer Research, Department of Neurobiology, Care Sciences and Society, Karolinska Institutet, Stockholm, Sweden

14 Theme Aging, Karolinska University Hospital Stockholm, Stockholm, Sweden

15 Alzheimer Center Amsterdam, Department of Neurology, Amsterdam Neuroscience, Vrije Universiteit Amsterdam, Amsterdam UMC, Amsterdam, The Netherlands

16 Clinical Neurochemistry Laboratory, Sahlgrenska University Hospital, Gothenburg, Sweden

17 Department of Neurodegenerative Disease, UCL Queen Square Institute of Neurology, London, UK

18 UK Dementia Research Institute at UCL, London, UK

19 Memory Clinic, Geneva University Hospitals, Geneva, Switzerland

20 Diagnostic Department, University Hospitals of Geneva, Geneva, Switzerland

21 Memory Clinic, Skåne University Hospital, SE-205 02 Malmö, Sweden 